\title{
The effect of immigration shocks on native fertility outcomes: evidence from a natural experiment
}

\author{
Kelvin K. C. Seah ${ }^{1,2}$ (D)
}

\author{
Correspondence: kelvinseah@nus. \\ edu.sg \\ ${ }^{1}$ Department of Economics, \\ National University of Singapore, 1 \\ Arts Link, Singapore 117570, \\ Singapore \\ ${ }^{2}$ IZA, Bonn, Germany
}

\begin{abstract}
This paper investigates whether immigration shocks have a causal effect on native fertility patterns. It uses a natural experiment, exploiting the large, unexpected and localised immigration of Cuban nationals to the Miami area in the USA in 1980 to examine the fertility consequences for non-Cuban Miami women. Using a synthetic control estimator and an extended individual difference-in-differences analysis, the results from this study indicate that the immigration shock had an overall negative, though short-lived, impact on the fertility of Miami women. In addition, fertility effects are found to vary by homeownership: While the immigration shock had a considerable negative impact on the fertility of women living in rented homes, it had no effect on those living in owned homes. This differential impact was likely due to the rise in local housing rents accompanying immigration, making childbearing less affordable for those living in rented homes.
\end{abstract}

JEL Classification: J61, J13

Keywords: Immigration, Fertility, Natural experiment, Synthetic control

\section{Introduction}

This paper examines whether immigration shocks have a causal effect on native fertility patterns. While there has been a plethora of previous research examining the effects of immigration on the labour market outcomes of destination countries, relatively few studies exist with a focus on exploring how immigration affects the host society in other ways. An area which research has hitherto neglected is the relationship between immigration shocks and native fertility behaviour. Yet, a synthesis of the research conclusions from studies exploring the effects of immigration on local destination markets with those investigating how fertility outcomes respond to economic conditions reveals that it is possible for native fertility outcomes to be altered by such inflows.

Immigration shocks may influence the childbearing decisions of natives through at least four channels: Firstly, among labour market participants, if natives view immigrants as competitors competing for scarce employment opportunities in the labour market, then an immigration influx may lead to increased perceptions of job insecurity among these workers. Presupposing that childbearing decisions depend positively on employment and income security (Sobotka et al. 2011), an increase in perceived job

(c) The Author(s). 2018 Open Access This article is distributed under the terms of the Creative Commons Attribution 4.0 International License (http://creativecommons.org/licenses/by/4.0/), which permits unrestricted use, distribution, and reproduction in any medium, provided you give appropriate credit to the original author(s) and the source, provide a link to the Creative Commons license, and indicate if changes were made. 
and income insecurity may act to reduce fertility (either contemporaneous/tempo or completed fertility, or both) by inducing individuals to delay their childbearing plans or to forgo having a child altogether. ${ }^{1}$ Secondly, an immigration shock may lead, at least in the short run, to an increase in housing prices and rents. To the extent that housing is a precondition for childbearing, an increase in housing rents/prices lowers a household's real income and exerts a negative income/substitution effect on the demand for children (Yi and Zhang 2010). ${ }^{2}$ By increasing the cost of raising a child, an increase in the price of living space can also impact fertility by increasing the likelihood that individuals postpone childbearing (Ranjan 1999). Thirdly, if incoming immigrants are composed of workers who are very substitutable to native women, and if the earnings of this group of natives are depressed as a result (Blau and Mackie 2017), then this could reduce the opportunity cost of childrearing and consequently increase the incentive to have children. Lastly, immigration can affect native fertility through local price changes. Prior studies that investigate the effects of immigration on prices (Cortes 2008) find that an increase in the share of low-skilled immigrants in a city's labour force leads to a reduction in the local prices of immigrant-labour-intensive services such as housekeeping and babysitting. Insofar as low-skilled immigration reduces the cost of childbearing and the conflict that native women have over childbearing and work, an increase in low-skilled immigration may work to increase native fertility (Furtado and Hock 2010; Furtado 2016).

There are two main research questions which this paper seeks to address: Firstly, do immigration shocks affect native childbearing decisions? Secondly, do childbearing responses to an immigration shock vary by homeownership status? The second question arises because, by changing the price of living space, immigration could potentially change the cost of childbearing differently for homeowners and non-homeowners.

This study uses a "natural experiment", exploiting the 1980 Mariel Boatlift where some 125,000 Cuban immigrants arrived in Miami over a 5-month period (May to September 1980) in order to generate an exogenous variation in immigration flow so that the fertility consequences of Miami women in the aftermath of the shock can be studied. The fertility impact of the immigration shock is measured in two ways. First, I apply the synthetic control estimator, using aggregate-level data, and assess the significance of the estimates using placebo tests. Second, I apply the traditional difference-indifferences estimator with inference techniques based on individual-level data. Both lead to the same conclusion: The immigration shock led to short-term declines in native childbearing activity in 1983 and in 1986, although these declines were compensated by fertility increases in later years. The short-term declines in native childbearing activity after the immigration influx were possibly due to individuals delaying their childbearing plans.

\section{Background}

\subsection{Literature review}

A number of studies have documented the way in which natives have responded to immigration inflows. Negative attitudes towards further immigration can arise, in part, due to native workers' perceptions that immigrants constitute a threat to their labour market opportunities and, in part, due to racial prejudice (Scheve and Slaughter 2001; Daniels and Von der Ruhr 2003; Mayda 2006; Dustmann and Preston 
2007). Because certain groups of native workers may perceive immigrants to threaten their labour market opportunities, it seems reasonable to expect that some natives would perceive their jobs and future streams of incomes to be less secure with an immigration shock.

The link between employment/income uncertainty and fertility behaviour has also been well explored, with many studies reaching conclusions which support the hypothesis that increases in job and income insecurity generally lower fertility-either temporarily, through delayed childbearing, or permanently, through a reduction in the number of children considered optimal (Ranjan 1999; Adsera 2004; Hondroyiannis 2010; Adsera and Menendez 2011; Bhaumik and Nugent 2011; Sobotka et al. 2011).

The effects of immigration on the housing market have been considered by a number of researchers. The general consensus, especially for studies examining housing markets in the USA, is that immigrant inflows lead to higher local housing prices/rents in the short run (Saiz 2003, 2007; Ottaviano and Peri 2012; Gonzalez and Ortega 2013).

Though recent, a number of studies which examine the relationship between the price of living space and fertility have also found evidence that housing affordability impacts fertility positively. For example, Simon and Tamura (2009) find that increases in housing rents lead to delayed childbearing in the USA. Using data on Hong Kong, Yi and Zhang (2010) find that an increase in the price of housing significantly decreases total fertility rates in the territory. In contrast to these papers, two other studies demonstrate that movements in housing prices can affect the fertility decisions of homeowners and non-owners differently. Dettling and Kearney (2014) find that while an increase in housing prices in the USA leads to a fall in the birth rates among nonhomeowners, it has the opposite effect for homeowners. They argue that this arises because an increase in housing prices potentially increases accessible home equity for people who own a home and induces a positive income effect on their demand for children. On the other hand, because housing is a major cost associated with (additional) children, an increase in the price of housing exerts a negative substitution effect on the current-period demand for children for people who do not own a home. Therefore, contemporaneous fertility of non-owners falls with rising house prices. Lovenheim and Mumford (2013) reach similar yet distinct conclusions, showing that while an increase in the price of housing leads to a marked increase in the probability of having a child among homeowners, it leaves fertility among renters unchanged.

The aforementioned studies indicate that immigration shocks may lead to an increase in perceived job insecurity among native workers and to higher housing prices/rents in the destination localities. It also indicates that the price of living space and people's perceptions about their future economic positions do affect childbearing decisions. Taken together, the above studies seem to imply that it is possible for increased immigration flows to induce a fall in native fertility. However, this need not necessarily be the case. On the contrary, a greater share of immigrants-especially if these are low-skilled-can be consistent with an increase in native fertility.

This could be the case, for instance, if the immigration shock is composed of workers who are very substitutable to native women (Blau and Mackie 2017). If so, any immigration-induced fall in wages and/or employment opportunities for this group of natives may decrease the opportunity cost of childrearing and therefore increase their likelihood of having children. 
In addition, prior empirical studies that investigate the effects of immigration on prices in the destination countries have found that an increase in the share of immigrants may lead to a reduction in the prices of goods and services in the locality (Lach 2007; Cortes 2008). To the extent, therefore, that immigration reduces the cost of child bearing and rearing and the conflict that native women have over childbearing and work, it is possible, as well, for increased immigration flows to affect native fertility positively (Furtado and Hock 2010; Cortes and Tessada 2011; Furtado 2016).

The above review has highlighted the possibility that immigration flows may have an effect on native fertility in the destination countries. However, the direction in which native fertility moves with immigration is a priori ambiguous. While an increase in the price of living space and a reduction in perceived job security following an immigration shock will likely exert a negative effect on the contemporaneous demand for children, the lower price of domestic services complementary to childbearing resulting from largely unskilled or less-skilled immigration flows or a fall in the wages or employment opportunities of native groups most substitutable to the incoming immigrants will tend to create a positive effect.

\subsection{The Mariel Boatlift}

The 1980 mass exodus from Cuba, popularly known as the Mariel Boatlift, can be used as a natural experiment to study the effects of a large and unanticipated immigration wave on the fertility outcomes of host country natives. Card (1990) documents that some 125,000 Cuban immigrants arrived in Miami from May to September 1980, driven by Fidel Castro's unexpected announcement on April 201980 that Cubans wishing to emigrate from the country were free to do so. Card's estimates suggest that $50 \%$ of the Mariel immigrants eventually settled in Miami, increasing the overall labour force of Miami by approximately 7\%. In a related study examining the response of housing markets to immigration shocks, Saiz (2003) estimates that the influx increased Miami's renter population by at least $9 \%$ in just 1 year (in 1980).

Although the original analysis of the wage impact of the Mariel Boatlift by Card (1990) did not find any notable impact of the supply shock on the labour market outcomes of Miami residents, recent re-examinations by Borjas (2017a, b) and Borjas and Monras (2016) suggest that Card's findings might have been flawed due to the way the comparison cities were chosen. In particular, Borjas (2017a) points out that the four cities used by Card (1990) to form the comparison group-Atlanta, Los Angeles, Houston, and Tampa-St. Petersburg-were selected partly based on their similarity in labour market trends with Miami after the Boatlift. This is problematic because, if the immigration shock truly worsened labour market conditions for existing residents in Miami after the shock, then the cities in Card's comparison group would be chosen, so that they too would have experienced worse labour market outcomes in that same period. As such, trends exhibited by this comparison group would spuriously resemble those exhibited by Miami in the post-Mariel period, giving one the false impression that the Boatlift had no impact on the labour market outcomes of Miami residents.

Borjas' (2017a) re-examination, which involved selecting the comparison group based on a data-driven method proposed by Abadie and Gardeazabal (2003) (which will be detailed in Section 4.1), finds that the wages of the least-skilled workers in Miami fell 
relative to those in the control cities after the Boatlift, suggesting that the shock had a negative impact on the wages of Miami workers whose skills and occupational choices were most similar to the Mariel Cubans. ${ }^{3}$ Borjas estimates that between 1977 and 1979 (pre-Boatlift) and 1981 and 1986 (post-Boatlift), the average wage of the least-skilled Miami workers declined substantially, by between 10 and 30\%. Interestingly, he finds the negative wage impact to be larger between 1984 and 1986 than between 1981 and 1983. ${ }^{4}$ Wage effects were found to weaken after 1986 and to disappear by 1990 . This suggests that Miami residents-notably the least-skilled ones-could have perceived their labour market opportunities to be threatened by the arrival of the immigrants.

It should be noted that the findings of Borjas (2017a) have been criticised by a number of studies, including Peri and Yasenov (2017) and Clemens and Hunt (2017). Peri and Yasenov (2017) argue that the large adverse wage impacts found in Borjas (2017a) is likely an artefact of measurement error due to the small sub-sample analysed and the matching of Miami to a control group of cities based on an inadequately short pretreatment period. $^{5}$ Any difference in labour market trends between Miami and the control group in the post-Boatlift period is therefore likely to be largely reflecting chance variation rather than the impact of the Boatlift, they argue. Clemens and Hunt (2017) argue that right around the time of the Boatlift in 1980, there had coincidentally been an increase in the share of Blacks in the Miami subsample which was analysed by Borjas (2017a). This compositional change was specific to Miami and was due to reasons unrelated to the Boatlift. They contend that because the wages of Blacks were lower than those of non-Blacks, the compositional change gave a misleading appearance that wages of the least-skilled workers in Miami had been negatively affected by the Boatlift.

Borjas attempts to respond to these criticisms in Borjas (2017b), where he adjusts for the increasing number of Black men in Miami's low-skilled workforce, by examining trends in race- and age-adjusted wages for Miami before and after the Boatlift. He shows that the results in Borjas (2017a) are robust to racial composition adjustments and demonstrates that the racial composition explanation offered by Clemens and Hunt (2017) is unlikely to be the reason for the observed fall in wages of the least-skilled Miami workers.

At the time of writing this paper, the debate between Borjas and these authors remains contentious and unresolved.

Nonetheless, if Borjas' findings about the heterogeneous impacts of the Boatlift on the labour market outcomes of workers by skill were true, one would expect lowskilled native women to respond differently in terms of their fertility behaviour than high-skilled women. ${ }^{6}$

Saiz's (2003) analysis of the housing market in Miami following the Mariel Boatlift presents further evidence of effects generated by the Boatlift. Estimates from the study indicate that the Boatlift led to rents in Miami increasing by 8 to $11 \%$ more in real terms relative to those in three groups of comparison metropolitan areas from 1979 to 1981. While the increase in the price of living space in Miami is likely to exert a negative price effect (or a negative real income effect) on the childbearing decisions of non-homeowners, it may have a positive income effect on the fertility decisions of homeowners (Ranjan 1999; Dettling and Kearney 2014).

Although there has not been any research documenting the effects of the Mariel influx on the local prices in Miami, the study by Cortes (2008) gives an indication of how the 
price of goods complementary to childbearing in Miami was likely to change following the Boatlift. Using data from the US consumer price index, the study finds that a higher share of low-skilled immigrants in the labour force reduces the price of immigrantlabour-intensive services such as babysitting and housekeeping. This suggests that the prices of goods and services complementary to childbearing could have declined (or at least risen at a slower rate than it otherwise would) in the aftermath of the Boatlift. This may have produced a positive price effect for fertility outcomes in Miami.

\section{Data}

\subsection{Current Population Survey June Supplements}

The main data source for this study is the United States Bureau of Labor Statistics' 1973 to 1988 Current Population Survey (CPS) June Supplements. ${ }^{7}$ The survey is administered during the month of June annually to persons in the civilian noninstitutional population of the USA and is intended to supplement fertility information on respondents in addition to its primary purpose of providing information on the employment position of US residents.

The survey provides information on each respondent's demographic, educational, income, and geographic characteristics; labour force activity; and marital history. Questions on fertility history were asked of all women aged 18 to 75 regardless of whether they were married and were asked of women aged 15 to 17 if they had ever been married. Responses to the fertility history provide, among other information, data on the month and year of respondents' most recent child and the number of births that a respondent has had. Approximately 60,000 households were interviewed during each survey in June. The units of observation are individuals within households.

The CPS sample is intended to be representative of the civilian non-institutional population of the USA and weights are provided so that estimates from the samples can be extrapolated to the wider population. Because geographical information on a respondent's residence is given, this allows respondents to be sorted by metropolitan areas (MSAs) within the USA. A total of 27 MSAs exist in the dataset. ${ }^{8}$ One limitation with the use of the CPS data is that prior to 1994, information on a respondent's nativity/citizenship is not provided. There is therefore no way to tell if a respondent was native or foreign born. Hence, we will take "natives" to mean all persons of non-Cuban origin residing in the USA.

Although the use of the difference-in-differences technique to identify changes in fertility outcomes in Miami following the Mariel Boatlift only requires aggregate data on fertility outcomes (that is, it simply requires one to have information on, say, aggregate birth rates), using micro-level data to construct aggregate fertility rates as with the CPS brings about several advantages over the use of readily available aggregate birth rate data.

Firstly, it allows one to control for individual-level characteristics that may influence individual fertility decisions and aggregate fertility outcomes.

Secondly, because the CPS allows for individuals in the sample to be identified based on ethnicity; it allows one to construct aggregate fertility rates pertaining only to nonCubans. Excluding Cubans from the analysis is important because (1) we intend to restrict the scope of this study to evaluate the effects of an immigration shock on the fertility outcomes of natives-that is, residents already living in Miami prior to the Boatlift, 
and (2) it is difficult to distinguish between births occurring to Cubans that settled in Miami prior to the Boatlift from those occurring to the Mariel Cubans. Because theory is unclear on how the fertility outcomes among the Mariel Cubans themselves would be affected by large-scale emigration, all births pertaining to women of Cuban descent are removed from the analysis. In contrast, aggregate birth rate data from the US vital statistics are not tailored to pertain specifically to the non-Cuban population.

Thirdly, the childbearing performance of individuals in a metropolitan area (i.e. metropolitan area-level fertility) is not well captured by readily available aggregate fertility data such as those from the US vital statistics. In particular, vital statistics report crude birth rates-defined as the annual number of births occurring in a metropolitan area per 1000 persons living in the area. This is a somewhat crude measure of metropolitan fertility since it normalises the number of births occurring in a metropolitan area to the entire metropolitan population rather than to the population most likely to have children (i.e. women of childbearing age). Say for the sake of exposition that a metropolitan area's crude birth rates increase over time. We cannot be sure if the increase in birth rates is due to an actual increase in childbearing activity in the area, which is what we are really interested to know, or to a relative decline in the (male) population in that area during this time. The aggregate fertility measure I construct using the CPS, known as the general fertility rate-defined as the annual number of births occurring in a metropolitan area per woman age 15 to 44 (i.e. the childbearing age)-overcomes this shortcoming by normalising births to a more "at risk" population (i.e. women of childbearing age), enabling me to conduct the analysis with a more refined measure of fertility (Namboodiri 1996).

\subsection{The sample}

I include in the sample all females age 15 to 44 . Women in this age range are typically found to have the greatest chance of childbearing. Because a considerable share of childbirths occurred out of wedlock, there is reason to believe, at least for the years analysed, that fertility outcomes need not be tightly linked to the institution of marriage in the USA (Willis 1999). ${ }^{9}$ Both married and unmarried women are therefore included in the sample. The non-Cuban sample from Miami includes an average of approximately 200 observations per year while the sample including Cubans includes an average of roughly 250 observations per year.

\subsection{Patterns in general fertility rates: $1973-1988$}

The evolution in general fertility rates from 1973 to 1988 for non-Cuban Miami women age 15-44 are shown in Table 1.

As can be seen, fertility rates fell sharply in 1983 and remained fairly low till 1984. However, in 1985, fertility rates returned to and even exceeded the high early 1980s levels. Fertility rates fell again in 1986 but exhibited an upward trend thereafter.

Assuming it takes approximately 2 to 2.5 years for the Mariel Boatlift to affect the childbearing outcomes of Miami residents through the hypothesised channels, the trends observed in Table 1 are consistent with a temporary delay in the timing of childbearing after the Boatlift (so that contemporaneous fertility falls sharply from 1982 to 1983 and remains low till 1984) and a "catch up" phase where fertility rises above its 


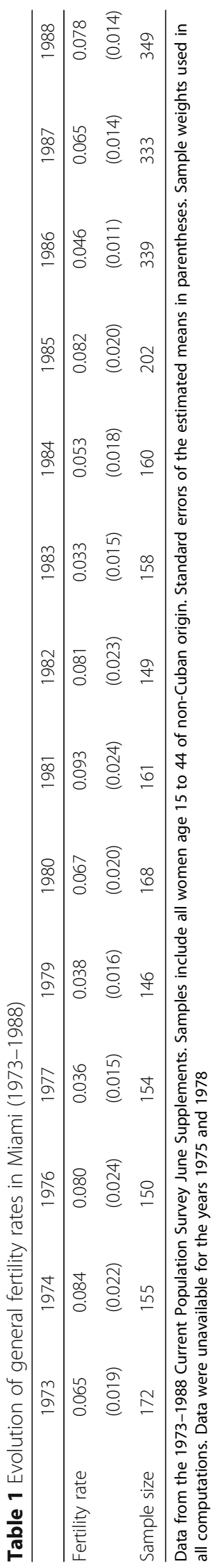


"normal" levels in the later years (from 1984 to 1985) ${ }^{10}$ It is not clear how the sharp fall in fertility rates observed in 1986 (and the recovery thereafter) should be interpreted and whether it is appropriate for us to attribute it to the Mariel Boatlift since we would expect any fertility impacts to diminish with time. The fall in 1986 is consistent, though, with results from Borjas (2017a, b), which show that the adverse wage effect of the Mariel Boatlift was not at its largest right after the immigration shock, but rather, only some 3 to 4 years later in 1984-1986. The patterns therefore do not preclude the possibility that a double decline in fertility may have occurred.

\section{Synthetic control analysis}

This paper employs a "natural experiment" to examine whether immigration shocks have a causal effect on native fertility. I adapt the study, originally used by Card (1990), to investigate the impact on native fertility in Miami after it received a large and unexpected inflow of migrants from Cuba between May to September 1980. The impact of the Mariel immigration shock is estimated by comparing the evolution of fertility outcomes for Miami after the immigration shock to those for comparable geographic regions within the USA which were unaffected by the shock.

The idea is that the evolution in the fertility outcomes for the control regions can be used as counterfactuals to estimate how fertility outcomes in Miami would have evolved, in the post-treatment period, had the Mariel Boatlift not occurred. Hence, by comparing the actual evolution of fertility outcomes for Miami after the immigration shock to the counterfactual evolution provided for by the control regions, one is able to estimate the fertility impacts of the immigration shock.

In all subsequent analyses, I take the year 1982 to be the first year for which fertility outcomes in Miami are likely to be affected by the immigration shock. The year 1982 therefore represents the start of the post-treatment period. While it is possible that fertility outcomes might have been affected in as early as 1981, the likelihood of this is low. The reason is that if a respondent reports having a birth in the last 12 months during the 1981 survey (conducted in June 1981), this would mean that the birth(s) must have occurred between the period July 1980 and June 1981. Because it takes an average of 42 weeks (or 9.7 months) between the time of conception and the time of delivery, the decision to have the child must have been made, at latest, between September 1979 and August 1980. Although the Mariel immigrants arrived in Miami between May 1980 and September 1980, slightly overlapping with this period, it is unlikely that either perceived job market security or the price of living space and goods complementary to childbearing would have adjusted fast enough so as to alter the childbearing outcomes reflected in the 1981 data. In any case, to be sure, robustness checks were conducted in all analyses to see if the results changed in any way when 1981 and 1983 were instead taken to be the start of the post-treatment period. The results remained practically unchanged when these alternative years were taken to be the years in which the treatment occurred. I therefore take 1982 to be the treatment year.

The raw data showing the evolution of fertility rates in Miami indicated that the rates fell sharply twice in Miami (once in 1983 and once in 1986) after the Boatlift. Although this is consistent with an interpretation that the Mariel Boatlift had a short-term negative effect on the fertility of non-Cuban women, we cannot be certain that the observed declines in fertility were due to the Boatlift rather than 
other confounding factors (e.g. common fertility shocks affecting all metropolitan areas in the USA) unless we know how fertility outcomes would have evolved in Miami in the absence of the immigration influx.

Ideally, we would like to know how fertility outcomes in Miami would have evolved during the period post-1982 in the absence of the immigration shock so that we can compare this evolution to the actual post-1982 evolution to identify whether the observed declines in fertility were indeed the result of the influx. If one had knowledge regarding how fertility outcomes would have evolved in Miami in the alternative world where Miami had not been affected by the Mariel influx, then one can compare the actual evolution of fertility outcomes in Miami to this counterfactual evolution to identify the impact of the Boatlift on fertility.

Although it is impossible to observe the fertility outcomes in Miami in the absence of the Mariel Boatlift, it is possible to approximate how fertility outcomes in Miami would have evolved in the counterfactual situation if we can find a suitable comparison area (or a group of comparison areas) which was unaffected by the Mariel influx and which is able to closely mirror Miami in terms of its characteristics and attributes. The fertility changes pertaining to such a comparison area will provide a counterfactual for the fertility changes for Miami.

Because I rely on the aforementioned strategy to identify the casual effect of the immigration shock, the comparison areas have to be carefully selected so that they are representative of Miami. There are a number of ways to select the comparison areas against which the fertility path of Miami can be compared. One strategy is to "hand-select" comparison metropolitan areas on the basis of subjective measures of similarity between the treated (i.e. Miami) and non-treated units (see, for example, Card (1990)). However, this approach has been criticised for being "adhoc" and of lacking clarity and objectivity in the way comparison units are chosen (Abadie et al. 2010). An alternative strategy, first proposed by Abadie and Gardeazabal (2003) and later formalised by Abadie et al. (2010), involves constructing comparison areas based on a data-driven procedure. This strategy-known as the synthetic control method-involves constructing a comparison area based on a convex combination of individual metropolitan areas with weights chosen so that the resultant comparison area resembles the treated area closely in term of its characteristics (i.e. characteristics relevant for predicting the outcome(s) of interest) before the treatment.

The weighted average of the contributing metropolitan units is conceptualised as the "synthetic twin" of the treated area and the outcome changes pertaining to this resultant comparison area in the post-treatment period are taken to reflect how outcomes in the treated area would have changed, absent the treatment. Since the synthetic comparison area is constructed to resemble the treated area, the selection procedure provides one with greater confidence that any observed differences in the changes in fertility outcomes between the treated and control areas are due to the immigration shock rather than to poor identification design-wherein differences arise only because the treated and comparison areas are fundamentally different to start with.

Because of the advantages presented by the synthetic control method developed by Abadie et al. (2010) over the more adhoc technique, I employ this method to reproduce the counterfactual fertility path for Miami in the absence of the Boatlift. 


\subsection{The synthetic control method}

This section briefly reviews the material developed in Abadie et al. (2010) in order to demonstrate the rationale behind the synthetic control technique. Interested readers may refer to Abadie et al. (2010) for further details on the method.

Suppose there are $t=1,2 \ldots, T$ time periods. Let $T_{0}$ be the number of pretreatment periods, where $1 \leq T_{0} \leq T$. Also, let $\boldsymbol{X}_{1}=\left(Y_{11}, \ldots, Y_{1 T_{0}}, \boldsymbol{Z}_{1}^{\prime}\right)^{\prime}$ be a vector of pre-treatment characteristics for Miami that includes the fertility outcomes in each year of the pre-treatment period (i.e. $Y_{11, \ldots,}, Y_{1 T_{0}}$ ) as well as covariates that are predictive of metropolitan area fertility (given by the vector $Z_{1}$ ). Similarly, let $\boldsymbol{X}_{0}$ be a matrix containing the same variables for each of the $J$ metropolitan areas potentially contributing to the comparison synthetic control unit. ${ }^{11}$ The idea behind the synthetic control method is to choose an optimal weighting vector $W^{*}=\left(w_{2}^{*}, \ldots ., w_{J+1}^{*}\right)^{\prime}$ such that it minimises:

$$
\left\|X_{1}-X_{0} W\right\|
$$

subject to

$$
w_{j} \geq 0 \quad \text { and } \quad \sum_{j=2}^{J+1} w_{j}=1 \quad \text { for } \quad j=2, \cdots, J+1
$$

12

where $w_{j}$ represents the weight of metropolitan area $j$ in the synthetic control.

Each metropolitan area's contribution to the synthetic version of Miami would be given by the weights contained in the optimal weighting vector. In doing so, the synthetic control is designed to resemble the actual Miami in terms of its attributes in the pre-treatment period. The evolution in fertility outcomes pertaining to the synthetic control in the post-treatment period is then taken to be an approximation of the actual evolution in fertility outcomes that would have occurred in Miami had there not been the Boatlift. ${ }^{13}$ Any deviation in fertility trends experienced in Miami from that of the synthetic control in the post-treatment period is an indication of the impact of the immigration shock.

More formally, the average treatment effect is:

$$
\delta=\left(\overline{y_{2, \text { Miami }}}-\overline{y_{1, \text { Miami }}}\right)-\left(\overline{y_{2, \text { Control }}}-\overline{y_{1, \text { Control }}}\right)
$$

where $\overline{y_{2, \text { Miami }}}$ and $\overline{y_{1, \text { Miami }}}$ denote the average fertility in Miami in the post and in the pre-treatment period respectively, and where $\overline{y_{2, \text { Control }}}$ and $\overline{y_{1, \text { Control }}}$ are analogously defined for the "synthetic Miami".

The significance of these treatment impact estimates have to be probed subsequently using placebo tests. Put simply, the placebo test involves the following: for each metropolitan area in the potential collection of units contributing to the synthetic Miami, the process as described for Miami is repeated so that a synthetic comparison control is constructed for each area. Estimates of the treatment effects are then computed for each metropolitan area as if each had been affected by the Mariel Boatlift in 1980. The distribution of these placebo estimates then form a sampling distribution for the actual impact estimates with which to test against the hypothesis of null treatment effects.

The idea is that since the other metropolitan areas were not affected by the Mariel Boatlift in 1980, the evolution of fertility outcomes for these areas should, in principal, follow those of their synthetic controls closely. In other words, we should not see 
outcomes for these areas deviating from those of their synthetic versions in the posttreatment period. Hence, by comparing the estimated treatment effect for Miami to these placebo effects, one can ascertain the rarity of the magnitude of the treatment effect. The null hypothesis of zero treatment effects is rejected if there is clear indication that the changes in fertility outcome in Miami relative to its synthetic control after the Boatlift exceed in magnitude those pertaining to these other metropolitan areas. This inferential technique is akin to a permutation test because it allows one to assess if the effect estimated for Miami is large relative to the placebo effects estimated for some other metropolitan area drawn at random.

\subsection{Estimated impacts on fertility outcomes}

I assume that the immigration shock is localised only to Miami and that all other metropolitan areas in the USA contributing to the comparison groups are unaffected by it. Further, I assume that the immigration shock in Miami does not produce any spill-over effects by affecting the contemporaneous fertility decisions and outcomes of women living in the "unaffected" metropolitan areas.

We begin by discussing the evolution of fertility rates in Miami and its synthetic control for the period 1973-1988. The metropolitan areas contributing to synthetic Miami are New York, Chicago, Philadelphia, Baltimore, Cleveland, Houston, San Diego, New Orleans, Tampa St. Petersburg, and Portland, with panel A in Table 2 showing the exact weights assigned to these areas for the purposes of constructing the control. These

Table 2 Metropolitan areas contributing to synthetic controls

\begin{tabular}{lc}
\hline Panel A: MSA weights in synthetic Miami when fertility is measured with respect to women age 15-44 \\
MSA & Weight \\
New York & 0.023 \\
Chicago & 0.001 \\
Philadelphia & 0.180 \\
Baltimore & 0.027 \\
Cleveland & 0.078 \\
Houston & 0.288 \\
San Diego & 0.047 \\
New Orleans & 0.025 \\
Tampa St. Petersburg & 0.244 \\
Portland & 0.087 \\
Panel B: MSA weights in synthetic Miami when fertility is measured & with respect to women living in rented homes \\
MSA & Weight \\
Los Angeles & 0.454 \\
Indianapolis & 0.160 \\
New Orleans & 0.386 \\
Panel C: MSA weights in synthetic Miami when fertility is measured with respect to women living in owned homes \\
MSA & Weight \\
Philadelphia & 0.531 \\
Boston & 0.256 \\
Tampa St. Petersburg & 0.213 \\
\hline
\end{tabular}


metropolitan units were chosen based on the minimisation process given by condition (1) in Section 4.1 so as to best approximate Miami in terms of its characteristics (i.e. characteristics that are predictive of metropolitan fertility rates) and the fertility trends exhibited in the pre-treatment period. To this end, I include in the set of characteristics to be matched-the MSA marriage rate, ${ }^{14}$ the proportion of females in the labour force, the female unemployment rate, the male unemployment rate, the female unemployment rate 1 year ago, the male unemployment rate 1 year ago, the proportion of women in the MSA within each ethnic category, the proportion of women in each MSA within each family income category, the proportion of women within each 5-year age category, and the proportion of women within each educational attainment category. These variables were chosen because they have been identified in the fertility literature as being the most relevant for predicting fertility rates in MSAs. Notice that male and female unemployment rates are included separately as predictors of fertility outcomes. This is meant to account for the fact that male and female unemployment can impact the fertility outcomes of women differently. While higher male unemployment in an MSA is generally expected to lower fertility rates since male incomes are important in providing the financial resources necessary for childbearing, it is unclear how higher female unemployment would affect fertility. On the one hand, unemployment among females may induce them to enter motherhood since the opportunity costs associated with childbearing are now lower. On the other hand, unemployment and the reduced stream of income flows can lead women to refrain from entering into long-term financial commitments and in so doing, postpone or cancel childbearing plans (O’Donoghue and O’Shea 2006).

The average values of these predictors over the pre-treatment years 1973-1981 are tabulated in panel A of Table 3 for Miami and its synthetic counterpart. Apart from indicators measuring the proportion of women within each ethnic category, the values of the rest of the characteristics are remarkably similar for both Miami and the synthetic control during this period. The reason that the proportion of women in each ethnic category for the synthetic control does not match well those for Miami is because of Miami's unique racial composition during the pre-treatment period (which has persisted till today). Miami was the most immigrant-intensive MSA in the USA, and its population consisted of a much larger proportion of Cubans, African Americans, and Hispanics than any other MSA. As such, no convex combination of other MSAs is able to reproduce the ethnic composition of Miami.

Figure 1 plots the fertility rates experienced in the two areas over the period 1973-1988. The movements in fertility rates for Miami and its synthetic control are quite similar for the entire pre-treatment period (1973-1981). The similarity in pretreatment fertility trends and characteristics between Miami and the control suggests that the synthetic control provides a reasonable counterfactual for Miami in the absence of the Mariel Boatlift. The fertility patterns exhibited by the synthetic control over the post-treatment period (1982-1988) can therefore be used to predict how fertility outcomes in Miami would have moved from year to year in the absence of the Boatlift. As can be seen, outcomes begin to diverge between Miami and the control after 1982. While fertility rates in Miami declined sharply from 1982 to 1983, the rates in the synthetic control demonstrated an increase instead during this time. Fertility rates appear to return to a level close to that experienced by the synthetic control from 1984 to 1985 . However in 1986 , outcomes diverged again, with fertility rates in Miami 
Table 3 Characteristics relevant to predicting fertility rates

\begin{tabular}{|c|c|c|c|c|c|c|}
\hline \multirow[b]{3}{*}{ Variables } & \multicolumn{2}{|c|}{ Panel A } & \multicolumn{2}{|c|}{ Panel B } & \multicolumn{2}{|c|}{ Panel C } \\
\hline & \multicolumn{2}{|c|}{ Women age $15-44$} & \multicolumn{2}{|c|}{$\begin{array}{l}\text { Women in } \\
\text { rented homes }\end{array}$} & \multicolumn{2}{|c|}{$\begin{array}{l}\text { Women in } \\
\text { owned homes }\end{array}$} \\
\hline & Miami & Synthetic & Miami & Synthetic & Miami & Synthetic \\
\hline Married & 0.542 & 0.576 & 0.449 & 0.494 & 0.574 & 0.530 \\
\hline In the labour force & 0.613 & 0.594 & 0.587 & 0.658 & 0.620 & 0.618 \\
\hline Non-Hispanic White & 0.492 & 0.747 & 0.307 & 0.582 & 0.483 & 0.833 \\
\hline Non-Hispanic African American & 0.372 & 0.173 & 0.465 & 0.252 & 0.367 & 0.130 \\
\hline Other race & 0.016 & 0.015 & 0.012 & 0.033 & 0.042 & 0.012 \\
\hline Hispanic & 0.121 & 0.065 & 0.217 & 0.132 & 0.108 & 0.026 \\
\hline Family income below US\$5000 & 0.165 & 0.113 & 0.258 & 0.138 & 0.037 & 0.032 \\
\hline Family income US\$5000-US\$7499 & 0.091 & 0.100 & 0.119 & 0.162 & 0.017 & 0.051 \\
\hline Family income US\$7500-US\$9999 & 0.120 & 0.099 & 0.167 & 0.098 & 0.047 & 0.041 \\
\hline Family income US\$10,000-US\$14,999 & 0.228 & 0.222 & 0.221 & 0.227 & 0.161 & 0.140 \\
\hline Family income US\$15000-US\$24,999 & 0.261 & 0.266 & 0.188 & 0.266 & 0.369 & 0.297 \\
\hline Family income US\$25000 and above & 0.136 & 0.200 & 0.048 & 0.110 & 0.369 & 0.439 \\
\hline Current female unemployment rate & 0.058 & 0.070 & 0.055 & 0.059 & 0.055 & 0.066 \\
\hline Current male unemployment rate & 0.069 & 0.065 & 0.059 & 0.061 & 0.059 & 0.083 \\
\hline Female unemployment rate 1 year ago & 0.055 & 0.070 & 0.041 & 0.050 & 0.041 & 0.068 \\
\hline Male unemployment rate 1 year ago & 0.066 & 0.066 & 0.060 & 0.060 & 0.060 & 0.085 \\
\hline Age 15-19 & 0.190 & 0.209 & 0.138 & 0.129 & 0.213 & 0.244 \\
\hline Age $20-24$ & 0.207 & 0.206 & 0.238 & 0.274 & 0.182 & 0.165 \\
\hline Age $25-29$ & 0.195 & 0.191 & 0.252 & 0.247 & 0.117 & 0.134 \\
\hline Age $30-34$ & 0.165 & 0.161 & 0.173 & 0.169 & 0.212 & 0.158 \\
\hline Age 35-39 & 0.132 & 0.119 & 0.125 & 0.106 & 0.138 & 0.160 \\
\hline Age 40-44 & 0.111 & 0.115 & 0.074 & 0.075 & 0.138 & 0.139 \\
\hline 8 or less years of completed education & 0.075 & 0.075 & 0.067 & 0.095 & 0.060 & 0.035 \\
\hline 9 years of completed education & 0.064 & 0.063 & 0.077 & 0.057 & 0.064 & 0.055 \\
\hline 10 years of completed education & 0.086 & 0.083 & 0.093 & 0.100 & 0.066 & 0.088 \\
\hline 11 years of completed education & 0.078 & 0.078 & 0.079 & 0.065 & 0.067 & 0.066 \\
\hline 12 years of completed education & 0.385 & 0.410 & 0.388 & 0.360 & 0.428 & 0.429 \\
\hline 13 years of completed education & 0.083 & 0.077 & 0.112 & 0.067 & 0.086 & 0.075 \\
\hline 14 years of completed education & 0.085 & 0.066 & 0.070 & 0.084 & 0.093 & 0.083 \\
\hline 15 years of completed education & 0.025 & 0.026 & 0.010 & 0.030 & 0.030 & 0.026 \\
\hline 16 years of completed education & 0.088 & 0.088 & 0.074 & 0.098 & 0.069 & 0.092 \\
\hline 17 years of completed education & 0.013 & 0.014 & 0.013 & 0.012 & 0.016 & 0.022 \\
\hline 18 years of completed education & 0.018 & 0.020 & 0.018 & 0.032 & 0.021 & 0.028 \\
\hline
\end{tabular}

The values of the predictor variables in panel A are averaged over the entire pre-treatment period, 1973-1981. The values of the predictor variables in panels B and C are averaged over the pre-treatment period, 1980-1981. Apart from unemployment rates, all figures are proportions

declining more sharply from 1985 to 1986 relative to that for its synthetic control. After the occurrence of this second fertility dip in 1986, the fertility rate in Miami followed an upward trend, increasing continuously from 1986 to 1988. These movements are in contrast to those exhibited by the synthetic control, which did not show a sharp fall in fertility in 1986 and which exhibited a falling, rather than increasing, fertility pattern from 1986 to 1988. 


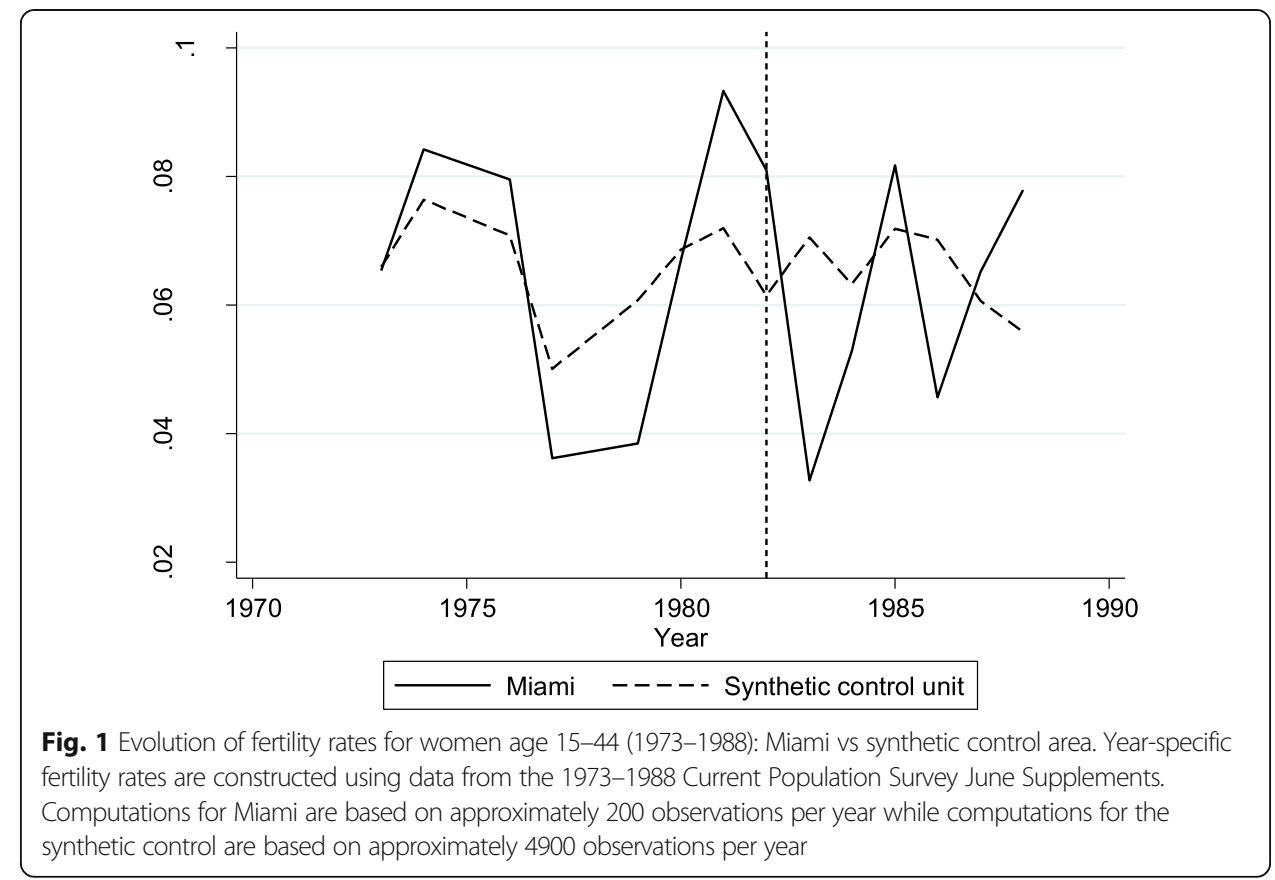

Since the synthetic control is supposed to reproduce the pattern of fertility outcomes that would have occurred in Miami in the years after 1982 in the alternative world where the immigration shock did not happen, the divergences in fertility paths between Miami and the synthetic control after 1982 provide support for our earlier postulate (based on raw fertility rate trends) that the Mariel Boatlift had a short-term negative impact on the fertility outcomes of natives in Miami (in 1983 and 1986). To be exact, actual fertility rates in Miami fell quite substantially-by 3.8 and $2.4 \%$ more than those predicted by the synthetic control respectively in 1983 and 1986. These year treatment effects are calculated based on Eq. (2), taking 1983 and 1986 respectively to be the post-treatment years and 1973-1981 to be the pre-treatment period. The negative fertility effect, however, was only temporary and was followed by a compensatory rise in fertility after each dip. This suggests that the Mariel Boatlift may have initially led to a postponement of childbearing among people in Miami but that this was subsequently compensated through a fertility rise in later years. ${ }^{15}$

Calculating the average treatment effect based on Eq. (2), and taking 1973-1981 to constitute pre-treatment years and 1982-1988 to constitute post-treatment years, one finds that fertility decreased by $0.2 \%$ in Miami after the influx relative to the synthetic control. However the magnitude of this estimate is sensitive to the pre- and posttreatment periods used. For example, if we instead take the pre-treatment period to be 1980-1981 and the post-treatment period to be 1983-1984-reflecting the outcomes just before and just after the treatment-then a very different conclusion is reached: In this case, fertility would have declined by $3.4 \%$ in Miami after the influx relative to the control. This is not surprising because the declines in fertility notably occur in 1983 and 1984. The smaller impact estimate obtained from using 1973-1981 and 1982-1988 as the relevant pre- and post-treatment periods masks the actual negative impact of the immigration shock because the decreases in fertility were only temporary, with fertility rising above predicted levels after each episode of fertility decline. ${ }^{16}$ 
Note that both Card (1990) and Saiz (2003) report that population growth rates in Miami slowed after the Mariel Boatlift. This may have occurred because natives living in Miami responded to the immigration inflow by moving out of Miami. It may also have occurred because the inflow deterred potential migrants living within the rest of the USA from moving to Miami. To the extent that the age distribution of women within the childbearing age (i.e. 15-44) group was significantly altered by the out-migration of existing Miami residents, inference on the effects of the immigration shock on fertility might be compromised (since age is an important predictor of childbirth). To check if the age distribution of women within the childbearing age group in Miami was altered after the Mariel Boatlift, we separate the female sample into six age categories: age 15-19, age 20-24, age 25-29, age 30-34, age 35-39, and age 40-44. An analysis was then conducted, where control units were selected based on the synthetic control method in order to evaluate whether a change in the proportion of women belonging to these age groups occurred. If so, then this would be indicative of a shift in the age composition of women in Miami following the Boatlift. The results from this analysis, which are not shown here for brevity but which are available from the author upon request, indicate that the Mariel Boatlift did not have any systematic effect on the age distribution of women in Miami. There therefore seems to be little need for worry about shifts in Miami's female composition introducing biases to the fertility impact estimates.

\subsection{Placebo tests for inference of fertility impact estimates}

The analysis presented in the previous sub-section revealed that actual fertility outcomes in Miami fell dramatically relative to the counterfactual outcomes predicted by the synthetic control in 1983 and 1986. Since the fertility trends exhibited by the synthetic control represent the counterfactual fertility path for Miami in the alternative world where the Boatlift did not occur, this suggests that the immigration shock led to a short-term decline in contemporaneous fertility during these years.

However, it would be sensible to suspect that these results may have been driven by chance. Indeed, it is possible that the divergences may have occurred because of the inability of the synthetic control method to reproduce the counterfactual fertility paths for Miami in the post-treatment period. If this is true, then the treatment effect estimates would be misleading. In order to test if the estimates are statistically significant, a series of placebo tests are performed. This involves applying the synthetic control method to each of the 26 metropolitan areas in the donor pool (i.e. metropolitan areas which were unaffected by the Mariel Boatlift in 1980) to see if the placebo effects generated for 1983 and 1986 for each metropolitan area are as large as the one obtained for Miami. In effect, what we want to know is whether we would see a negative fertility effect in 1983 and 1986 that is as large as the one seen for Miami if we happen to pick at random another metropolitan area for the study rather than Miami. If the placebo studies yield placebo treatment effects that are as large as the ones estimated for Miami, then this indicates that the analysis fails to provide sufficient evidence for the Mariel Boatlift having a temporary negative effect on fertility in Miami during these 2 years. On the other hand, if the placebo studies show that the treatment effects for Miami are unusually large relative to the placebo treatment effects estimated for the other metropolitan areas, then we can be more confident that the estimated treatment effects for Miami are not simply artefacts of chance, but that they 
instead represent genuine fertility impacts occurring in Miami during these periods, possibly driven by the Boatlift. Essentially, the placebo studies allow one to compare the magnitude of the treatment effects for Miami vis-a-vis the placebo effects for the unaffected metropolitan areas and thereby determine if the treatment effects for Miami are large and rare enough so that one can be confident about rejecting a hypothesis of null treatment effects.

As mentioned in Section 4.1, I construct a synthetic control unit iteratively for each of the 26 metropolitan areas in the donor pool and proceed as if each had been affected by the Mariel immigration shock in 1980. As with the case for Miami, the pretreatment period is taken to be $1973-1981$ and the post-treatment period is taken to be 1982-1988. I then measure the differences in outcomes between each metropolitan area and its synthetic control for each year, over the entire period 1973-1988. The differences in outcomes, or gaps, as I shall call them, in each of the post-treatment years represent the placebo treatment effects for each year. Of course, this procedure is also done for Miami in order to derive the actual treatment effects for each year. Such an iterative procedure therefore provides me with a distribution of one treatment and 26 placebo effects.

The results of the placebo test are presented in Fig. 2. Each grey line in the figure traces the yearly differences in fertility rates between each metropolitan area in the donor pool and its synthetic counterpart over the period 1973-1988. The dashed red line denotes the estimated yearly differences for the case of Miami. The estimated gap for Miami during the years 1982-1983 and 1985-1986 are large relative to those estimated for the other metropolitan areas in the donor pool. To reduce the subjectivity of this interpretation based on simple visual identification, I additionally conduct a more formal test of the significance of the treatment effect estimates as suggested in Bohn et al. (2014). This involves comparing the actual treatment effect estimates for 1983 and 1986 to the complete distribution of the other 26 placebo effect estimates to determine if the treatment effect estimates for 1983 and 1986 are indeed much more

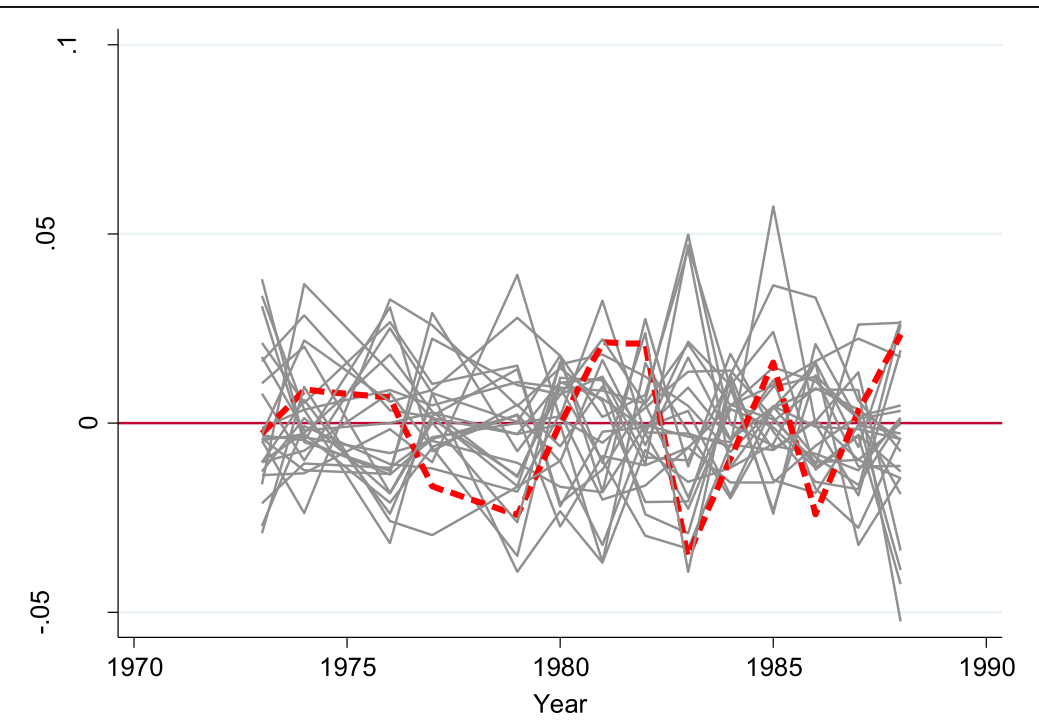

Fig. 2 Placebo test: Estimated fertility impacts for Miami and placebo fertility impacts for 26 comparison MSAs. Women age 15-44. Data from the 1973-1988 Current Population Survey June Supplements 
negative than the placebo estimates. A $p$ value for the one-tailed test of the likelihood of observing an estimate at least as negative as that for Miami can be computed for 1983 and 1986 by taking the rank of the estimates obtained for Miami and dividing this by 27 (since there are 26 placebo estimates and 1 treatment estimate). The estimate which is most negative receives a rank of 1 . The second most negative estimate receives a rank of 2 and so on. The $p$ value from the test is therefore bounded from below by 0.037 (i.e. 1/27). The lower the $p$ value for the treatment effect estimate, the more statistically significant the estimate since it implies that there is a low probability of obtaining placebo effects that are as large as the one obtained for Miami. Results from the more formal test reveal that the impact estimates obtained for Miami are the second most negative in 1983 and most negative in 1986, yielding $p$ values of 0.074 (i.e. $2 / 27$ ) and 0.037 respectively. This demonstrates that there is a low probability of obtaining gaps as large as the ones obtained for Miami during the years 1983 and 1986 and provides one with greater certainty that the estimated negative treatment effects found in these years are statistically significant.

\subsection{Individual difference-in-differences analysis}

The earlier analysis relied on aggregate data, albeit constructed from micro-level CPS data. ${ }^{17}$ To assess the robustness of the earlier results, I additionally test for impacts on the fertility outcomes of Miami residents using a more traditional difference-indifferences estimator with inference techniques based on CPS micro data.

Similar to the synthetic control approach, the identification strategy used here to estimate the impact of the Mariel influx is to compare native fertility outcomes in Miami, before-and-after the immigration shock, to those in comparable metropolitan areas that were unaffected by the shock. I conduct the difference-in-differences analysis using regression methods to control for differences in sample characteristics which may influence fertility outcomes. The primary regression specification I use is ${ }^{18}$ :

$$
\mathrm{FERT}=\alpha+\sum_{k=82}^{88} \delta_{k}\left(\operatorname{POSTYR}_{k} \times \text { MIAMI }\right)+Z^{\prime} \beta+u
$$

where FERT denotes the fertility status of an individual and is measured by a dummy variable indicating the incidence of a birth in the last 12 months. It is equal to 1 if the observation has had a birth in the past 12 months prior to the survey date and 0 otherwise. $\alpha$ is the intercept. POSTYR $k$ is a dummy variable equal to 1 if the observation is from the post-Boatlift year $k$ and equal to 0 otherwise. For instance, POSTYR 82 would be a dummy variable equal to 1 if the observation is from the year 1982 and equal to 0 otherwise, while POSTYR $_{88}$ would be a dummy variable equal to 1 if the observation is from the year 1988 and equal to 0 otherwise. $M I A M I$ is a dummy variable equal to 1 if the observation is from Miami and equal to 0 otherwise. POSTYR $k \times$ MIAMI denotes an interaction of the post-treatment year dummy with the MIAMI dummy. $Z$ is a vector of MSA- and individual-level covariates which control for other factors influencing individual-level fertility outcomes. $\beta$ represents a vector of coefficients on these covariates. Finally, $u$ represents the error term which captures unobserved effects influencing fertility.

This specification allows the impact of the shock on fertility to vary across the postinflux years and enables one to obtain separately-the treatment effects for each of the years following the Mariel Boatlift (i.e. 1982 to 1988). 
The parameters of interest are the ones on the interaction terms, $\delta_{k}$ (with $k$ running $82, \ldots, 88)$, since they measure the year-by-year change in fertility in Miami due to the immigration shock. A negative $\delta_{82}$ coefficient, for example, would indicate that the Mariel Boatlift had a negative impact on the fertility of Miami women in 1982. The opposite would be true if this coefficient is positive.

My estimation strategy is to begin with the simplest regression model by including only (a) MSA dummies and (b) year dummies in the vector $Z$. The purpose of the MSA dummies is to capture systematic metropolitan area differences in fertility assumed to be constant over time, while the year dummies are intended to capture time varying effects assumed to be constant across MSAs.

I next add additional covariates which influence fertility but which are likely to be exogenous to individual fertility outcomes. Included in this expanded list of covariates are the following: (c) age dummies-to capture systematic age differences in fertility; (d) dummy variables for ethnicity and family income-intended respectively to capture differences in fertility due to ethnic differences and family incomes; (e) number of previous births by the individual-to allow for the likelihood of a birth occurring to an individual to change as birth parity increases; and (f) MSA-level male and female unemployment rates 1 year prior to the survey ${ }^{19}$-to allow for the likelihood of a birth to vary with economic conditions. ${ }^{20}$

Next, I add covariates that potentially determine fertility outcomes but which are at the same time possibly endogenous to fertility outcomes. I add these variables successively to the regression specification to see whether their inclusion changes the estimated coefficients on the Year-Miami interaction terms. These covariates are (g) a variable indicating the level of completed education of an individual and (h) a dummy variable for marital status.

Covariates (g) and (h) are essentially choice variables that might depend on an individual's preference for having children. For example, if individuals have a preference for having (more) children, they may respond by choosing a lower level of education so as to increase their chances of fulfilling childbearing goals earlier. Also, since social norms might regard marriage to be a pre-requisite for family formation (Willis 1999), individuals may have a higher likelihood of entering marriage if they have a preference for (more) children.

Finally, I add two interaction terms: (i) an interaction term for ethnicity and education and an interaction term for ethnicity and marital status. These interaction terms are meant to account respectively for the possibility that the effect of education on fertility and the effect of marriage on fertility may be different for women of different ethnicities.

The purpose of starting with regression models with only MSA and year main effects and then adding groups of covariates in a successive manner is to allow one to identify whether there are sets of observable attributes which matter for selection (into whether or not an individual is exposed to the Mariel immigration by living in Miami from 1982). Adding the controls to the regression will change the coefficients on the posttreatment Year-Miami interaction variables if these controls are correlated with the Year-Miami variables, conditional on MSA and year main effects. We include controls for the wide range of demographic and economic characteristics described above because these are potential confounders, likely to be correlated with both the probability of a birth and the probability of being exposed to the Boatlift. 
The selection of metropolitan areas to form comparison groups which serve as counterfactuals for Miami is based on the synthetic control method (discussed in Section 4.1). This means that the metropolitan areas contributing to the comparison groups are the same as those presented in Section 4.2. In essence, this first involves sorting the individual-level observations by metropolitan areas, before using the weights derived from the synthetic control method to weigh the contributions for each observation to the comparison group.

We begin by focusing on the fertility outcomes pertaining to non-Cuban women of childbearing ages (women age 15 to 44). ${ }^{21}$ As with the synthetic control approach, the control group consists of observations from New York, Chicago, Philadelphia, Baltimore, Cleveland, Houston, San Diego, New Orleans, Tampa St. Petersburg, and Portland. I weigh each individual-level observation in these metropolitan areas by the weights shown in Table 2, panel A so that movements in aggregate fertility for the synthetic control resemble those for Miami in the pre-treatment period.

Table 4 presents results from a variety of regressions showing the estimated impact of the Mariel Boatlift on the fertility of non-Cuban women in Miami. The separate year treatment effects in Table 4 are the estimated coefficients on each of the separate post-treatment Year-Miami interaction variables: Each is obtained by running regression specification (3) using a different set of covariates as discussed earlier. Column (1) displays the estimates

Table 4 Estimated impact of Mariel Boatlift on fertility of women age 15-44 in Miami

\begin{tabular}{|c|c|c|c|c|c|}
\hline Included covariates & $\begin{array}{l}\text { (1) } \\
\text { (a)-(b) }\end{array}$ & $\begin{array}{l}(2) \\
\text { (a)-(f) }\end{array}$ & $\begin{array}{l}\text { (3) } \\
\text { (a)-(g) }\end{array}$ & $\begin{array}{l}\text { (4) } \\
\text { (a)-(h) }\end{array}$ & $\begin{array}{l}\text { (5) } \\
\text { (a)-(i) }\end{array}$ \\
\hline \multicolumn{6}{|c|}{ Separate-year treatment effects } \\
\hline \multirow[t]{2}{*}{1982} & 0.014 & 0.007 & 0.005 & 0.009 & 0.011 \\
\hline & $(0.025)$ & $(0.027)$ & $(0.027)$ & $(0.026)$ & $(0.026)$ \\
\hline \multirow[t]{2}{*}{1983} & $-0.041^{* *}$ & $-0.034^{*}$ & $-0.038^{*}$ & $-0.039^{*}$ & $-0.040^{*}$ \\
\hline & $(0.018)$ & $(0.021)$ & $(0.021)$ & $(0.020)$ & $(0.020)$ \\
\hline \multirow[t]{2}{*}{1984} & -0.007 & 0.007 & 0.004 & 0.004 & 0.005 \\
\hline & $(0.020)$ & $(0.023)$ & $(0.023)$ & $(0.023)$ & $(0.023)$ \\
\hline \multirow[t]{2}{*}{1985} & 0.012 & 0.006 & 0.005 & 0.008 & 0.008 \\
\hline & $(0.022)$ & $(0.023)$ & $(0.022)$ & $(0.022)$ & $(0.022)$ \\
\hline \multirow[t]{2}{*}{1986} & $-0.032^{* *}$ & $-0.036^{* *}$ & $-0.038^{* *}$ & $-0.039^{* *}$ & $-0.041^{* *}$ \\
\hline & $(0.015)$ & $(0.017)$ & $(0.017)$ & $(0.017)$ & $(0.017)$ \\
\hline \multirow[t]{2}{*}{1987} & 0.006 & 0.006 & 0.005 & 0.005 & 0.003 \\
\hline & $(0.017)$ & $(0.019)$ & $(0.019)$ & $(0.018)$ & $(0.018)$ \\
\hline \multirow[t]{2}{*}{1988} & 0.011 & 0.006 & 0.004 & 0.006 & 0.005 \\
\hline & $(0.017)$ & (0.019) & $(0.019)$ & (0.019) & $(0.018)$ \\
\hline Observations & 71,571 & 58,921 & 58,921 & 58,921 & 58,921 \\
\hline$R$-squared & 0.002 & 0.035 & 0.037 & 0.064 & 0.067 \\
\hline
\end{tabular}

Sample consists of women age 15-44. The comparison group encompasses all observations from New York, Chicago, Philadelphia, Baltimore, Cleveland, Houston, San Diego, New Orleans, Tampa St. Petersburg, and Portland. The control variables in column (1) include MSA and year dummies. The control variables in column (2) include MSA, year, age, ethnicity, and family income dummy variables as well as the number of previous births by the individual and MSA-level lagged male and female unemployment rates. The control variables in column (3) include all the control variables in column (2) plus the level of completed education of an individual. The control variables in column (4) include all the control variables in column (3) plus a dummy variable for marital status. The control variables in column (5) include all the control variables in column (4) plus an interaction term for ethnicity and education and an interaction term for ethnicity and marital status. Sample weights are used in all regressions. All specifications are estimated by OLS. Robust standard errors are in parentheses. ${ }^{* * *} p$ value $<0.01,{ }^{* *} p$ value $<0.05,{ }^{*} p$ value $<0.1$ 
from running specification (3) with only the MSA and year dummy variables included in the vector of covariates $Z$. Column (2) shows the estimates when the exogenous variablesnamely, the dummy variables for age, ethnicity and family income, the number of previous births occurring to the individual, and the MSA male and female unemployment rates 1 year ago-are added to the vector $\boldsymbol{Z}$. The estimates in columns (3) and (4) are obtained by including the plausibly endogenous variables-namely, the number of years of completed education and a dummy variable for marital status-successively in vector $Z$. Lastly, column (5) presents the estimated coefficients on the Year-Miami interaction terms when the full set of covariates (i.e. all variables listed from (a) to (i)) are included in the regression. ${ }^{22}$ As can be seen, the estimated fertility impacts change somewhat from columns (1) to (2) but are very similar across columns (2) through (5). This suggests that while assignment to exposure to the Boatlift depends importantly on the variables (c) to (f) (especially ethnicity and age), it depends less importantly, if at all, on the variables (g) to (i). The estimates from the regression with the full set of covariates included (i.e. column (5)) suggest that the Boatlift had a varying impact across the 7 post-treatment years. While it led to a $4.0 \%$ (significant at the $10 \%$ level) and a $4.1 \%$ (significant at the 5\% level) reduction in fertility in 1983 and in 1986, it had essentially no impact on fertility in the rest of the post-treatment years. ${ }^{23}$ These results are in agreement with those derived earlier using the synthetic control approach, demonstrating that the Mariel Boatlift had a significant negative impact on the fertility of non-Cuban Miami women in 1983 and 1986.

\subsubsection{Investigating fertility responses based on differences in homeownership}

The impact of immigration shocks on childbearing potentially differs by homeownership status. While an increase in the price of housing accompanying immigration will make childbearing more costly for non-owners (since housing and raising children are complementary), and so decrease their current-period demand for children, it could, by increasing accessible home equity, instead increase homeowners' demand for children (Lovenheim and Mumford 2013; Dettling and Kearney 2014). Further, rent increases due to immigration will leave non-owners with less financial resources for childrearing while providing homeowners with more. Hence, one would expect non-owners and owners to respond differently to the shock. In order to test for heterogeneous impacts, I repeat the above analysis, separating individuals by homeownership status.

In general, women can fall into one of three homeownership groups: Women can either be living in a home (a) owned or bought by a household member, (b) rented for cash, or (c) where occupation is free of charge (i.e. cash rents need not be paid). Because of the tiny number of observations belonging to category (c), I exclude women in category (c) from the analysis. Hence, women are either classified as living in an owned home (homeowner) or a rented home (renter). ${ }^{24}$

We first estimate the fertility impacts on homeowners and renters, separately, using specification (3). ${ }^{25}$ Column (1) of Table 5 (panel A) shows the fertility impacts of the Mariel Boatlift on women living in rented homes in Miami for each of the posttreatment years using this specification. ${ }^{26}$ For brevity reasons, only the result where the full set of controls (a) to (i) has been included is displayed. ${ }^{27}$ The estimated effects for all the post-treatment years are negative, with magnitudes ranging from a 1.3\% decline in fertility in 1982 to a $13.9 \%$ decrease in 1983 . Three of 7 of the year treatment effects-namely, 1983, 1984, and 1986 (all significant at the 1\% level)-are statistically 
Table 5 Estimated impacts of Boatlift on fertility of women living in rented and in owned homes

\begin{tabular}{|c|c|c|c|c|}
\hline \multirow[b]{4}{*}{ Included covariates } & \multicolumn{2}{|l|}{ Panel A } & \multicolumn{2}{|l|}{ Panel B } \\
\hline & (1) & (2) & (3) & (4) \\
\hline & Renters & Homeowners & Renters & Homeowners \\
\hline & (a)-(i) & (a)-(i) & (a)-(i) & (a)-(i) \\
\hline \multicolumn{5}{|c|}{ Separate-year treatment effects } \\
\hline \multirow[t]{2}{*}{1982} & -0.013 & 0.048 & 0.005 & 0.004 \\
\hline & $(0.044)$ & $(0.038)$ & $(0.038)$ & $(0.036)$ \\
\hline \multirow[t]{2}{*}{1983} & $-0.139^{* * *}$ & 0.013 & $-0.090^{* * *}$ & -0.009 \\
\hline & $(0.040)$ & $(0.038)$ & $(0.026)$ & $(0.032)$ \\
\hline \multirow[t]{2}{*}{1984} & $-0.129^{* * *}$ & $0.069^{*}$ & $-0.053^{*}$ & 0.044 \\
\hline & $(0.048)$ & $(0.041)$ & $(0.029)$ & $(0.037)$ \\
\hline \multirow[t]{2}{*}{1985} & -0.025 & 0.007 & 0.018 & -0.023 \\
\hline & $(0.043)$ & $(0.028)$ & $(0.036)$ & $(0.025)$ \\
\hline \multirow[t]{2}{*}{1986} & $-0.118^{* * *}$ & -0.005 & $-0.070^{* * *}$ & -0.037 \\
\hline & $(0.045)$ & $(0.027)$ & $(0.026)$ & $(0.024)$ \\
\hline \multirow[t]{2}{*}{1987} & -0.061 & 0.042 & -0.019 & 0.003 \\
\hline & $(0.039)$ & $(0.032)$ & $(0.029)$ & $(0.027)$ \\
\hline \multirow[t]{2}{*}{1988} & -0.032 & 0.021 & -0.008 & -0.007 \\
\hline & (0.039) & $(0.029)$ & $(0.028)$ & $(0.025)$ \\
\hline Observations & 7733 & 9903 & 44,963 & \\
\hline$R$-squared & 0.071 & 0.089 & 0.073 & \\
\hline
\end{tabular}

The estimated treatment effects in panel A are obtained by estimating Eq. (3), separately for the sample of renters (column (1)) and homeowners (column (2)). For column (1), the comparison group encompasses all observations from Los Angeles, Indianapolis, and New Orleans. For column (2), the comparison group encompasses all observations from Philadelphia, Boston, and Tampa St. Petersburg. The estimated treatment effects in panel B are obtained from estimating Eq. (4). Equation (4) includes variables where the post-treatment year-Miami terms are interacted with a dummy indicating homeownership status. The comparison group in columns (3) and (4) is the same as those in Section 4.2 and consists of New York, Chicago, Philadelphia, Baltimore, Cleveland, Houston, San Diego, New Orleans, Tampa St. Petersburg, and Portland. All samples consist of women age 15-44. In all regressions, we include as control variables: MSA, year, age, ethnicity, marital status, and family income dummy variables as well as the number of previous births by an individual, the MSA-level lagged male and female unemployment rates, the level of completed education of an individual, an interaction term for ethnicity and education and an interaction term for ethnicity and marital status. Sample weights are used in all regressions. All specifications are estimated by OLS. Robust standard errors are in parentheses. ${ }^{* *} p$ value $<0.01,{ }^{* *} p$ value $<0.05$, ${ }^{*} p$ value $<0.1$

significantly different from zero. This suggests that the Mariel Boatlift led to a longerterm decline in fertility outcomes among non-home owning women Fig. 3.

These results are in stark contrast to the fertility changes experienced by women living in owned homes. Column (2) of Table 5 (panel A) displays estimates of the separate-year fertility impacts for home-owning women in Miami. As with the case of renters, only the results where the full set of controls (a) to (i) has been included are displayed. ${ }^{28}$ Apart from the 1984 estimate, which is statistically significant at the $10 \%$ level, none of the estimated impacts are sizeable or significant. There is therefore little evidence that the Mariel Boatlift affected the fertility outcomes of home-owning women adversely. If anything, the Boatlift may instead have had a positive impact on their fertility.

Do the above conclusions change, if instead, we ran the analysis using an interaction term with homeownership status rather than over two distinct samples? This question is addressed by estimating Eq. (4), including in the vector $\boldsymbol{Z}$, the full set of control variables (a) to (i): 

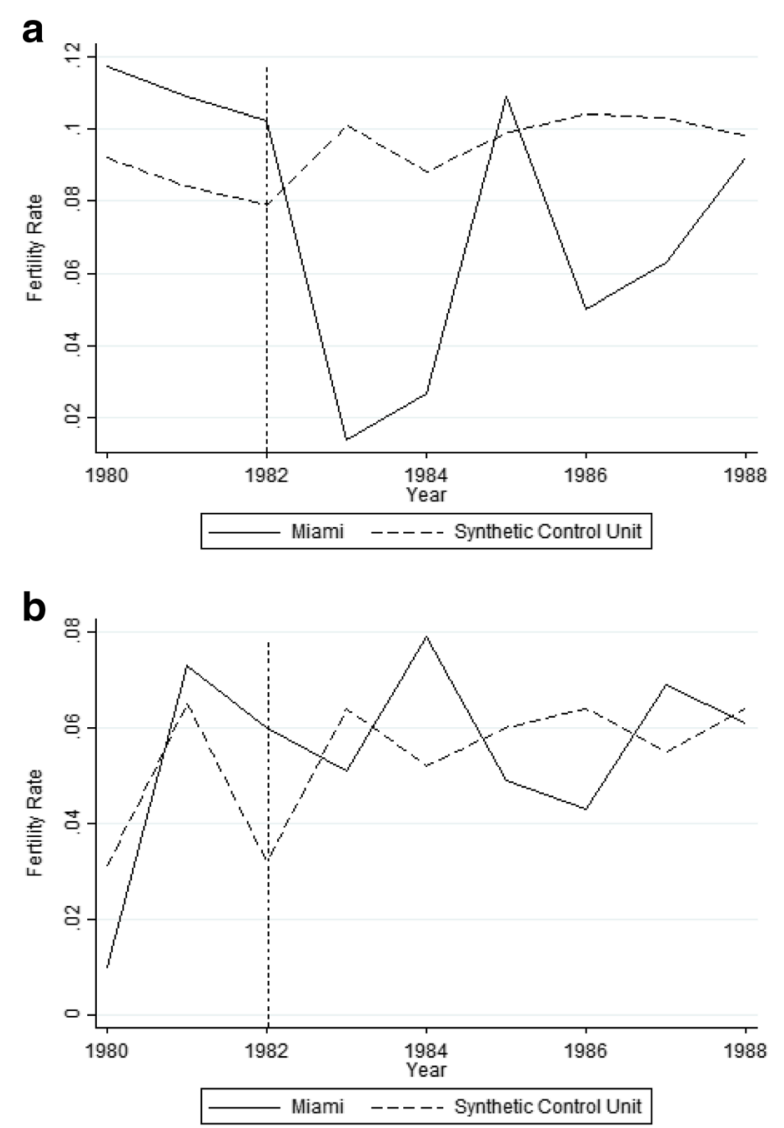

Fig. 3 Evolution of renter and homeowner fertility rates in Miami and synthetic control (1980-1988). a Evolution of renter fertility rates in Miami and in synthetic control. $\mathbf{b}$ Evolution of homeowner fertility rates in Miami and in synthetic control

$$
\begin{aligned}
\text { FERT }=\alpha & +\sum_{k=82}^{88} \delta_{k}\left(\text { POSTYR }_{k} \times \text { MIAMI }\right) \\
& +\sum_{k=82}^{88} \gamma_{k}\left(\text { POSTYR }_{k} \times \text { MIAMI } \times \text { RENTER }\right)+Z^{\prime} \beta+u
\end{aligned}
$$

Where RENTER is a dummy variable equal to 1 if the observation lives in a rented home and 0 otherwise. The separate Year-Miami interaction terms are as defined before. POSTYR $_{k} \times$ MIAMI $\times$ RENTER denotes a dummy variable obtained by interacting the three dummy variables: POSTYR ${ }_{k}$, MIAMI, and RENTER. Specification (4) allows the impact on fertility to vary with post-treatment year and by homeownership status. For instance, the impact of fertility outcomes in 1982 would be given by $\gamma_{82}$ RENTER $+\delta_{82}$ : it is equal to $\delta_{82}$ for homeowners (since RENTER is equal to 0 for homeowners) and equal to $\gamma_{82}+\delta_{82}$ for renters (since RENTER is equal to 1 for renters). Fertility effects pertaining to the other post-treatment years are similarly defined. The estimated fertility effects using this specification are reported separately for renters and homeowners in Table 5 (panel B). ${ }^{29}$ They paint a picture similar to the regressions run over the two distinct samples by homeownership status. ${ }^{30}$

Notice the differential impacts that the Mariel Boatlift had on the fertility outcomes of homeowners and renters. While the immigration shock appears to have led to a shortterm decline in fertility among renters, no such effect is observed for homeowners. These 
observations are consistent with the postulates by Dettling and Kearney (2014), which were earlier discussed in Section 2.1, and suggest that an important channel through which immigration shocks affect fertility is the housing market. ${ }^{31}$

One concern is whether the observed differences in fertility impacts between renters and homeowners might be spuriously driven by underlying heterogeneity along the skill dimension. After all, the correlation between homeownership status and skills is reasonably high, with a correlation coefficient of 0.18 between the binary variable indicating whether an individual is a renter and the binary variable indicating whether the individual is a high school dropout (renters are more likely to be high school dropouts). This concern is unlikely to be a problem here since the fertility impact estimates provided in Table 5 and in Appendix Table 8 were obtained from regressions that controlled for women's educational attainment. They are therefore skill-adjusted and they tell us the fertility impacts on renters and homeowners, conditional on skill level (as measured by education).

\subsubsection{Differences in fertility responses by skill}

In Section 2.2, it was noted that Borjas (2017a, b) had found wages of the least-skilled Miami workers to be negatively impacted following the Mariel shock. If his findings are correct, one would expect fertility responses of natives to differ also by skill level (since perceptions of job security and wages ought to be differently affected for low-skilled and high-skilled women). In particular, we would expect fertility effects to be concentrated on low-skilled women. Although it would be insightful to test as well if heterogeneous impacts exist across skill levels, this is not possible in practice. This is because of the tiny sample sizes which result when the sample is split by skill level. To see this, consider that, on average, there are only around 24 women age 25 to 44 with less than high school education (high school dropouts) in Miami each year. Sample sizes this small mean that fertility impact estimates would be very noisy. Statistical inference would therefore be problematic. Note that when analysing heterogeneity by skill level, a modification needs to be made to the age restriction of the sample. In particular, the lower bound of the age restriction should be increased from 15 (to something like 25). This is to ensure that only women who would be old enough to have had a choice between completing or dropping out of high school are analysed.

\section{Conclusions}

This paper represents the first attempt to identify a causal relationship between immigration flows and native childbearing outcomes. It identifies possible channels through which individual childbearing outcomes may be influenced by an immigration influx. The findings are relevant for public policy, especially for countries that are major providers of international refuge since governments would presumably like to know how a mass migration influx-initiated by, say, war, oppression, or political turmoil in the source countries-would affect the future fertility outcomes of their own native population. They are also useful for governments that have chosen to adopt, or are considering adopting, a strategy of relaxing immigration laws and encouraging both permanent and temporary migration into their territories to counter the problems of an ageing population-a phenomenon now common to many developed countries. The findings from this research provide an indication for whether such labour augmenting strategies are appropriate and the likely consequences for the childbearing outcomes of host country natives. 
This study uses a natural experiment, exploiting the large, unexpected and localised immigration of Cuban nationals to the Miami area in the USA in 1980 in order to examine the fertility consequences for non-Cuban women. The impact of the immigration shock is estimated by comparing the evolution of fertility outcomes for women living in Miami, after the shock, to those for women living in other areas of the USA unaffected by the Cuban immigration. This is done in two ways: firstly, by applying the synthetic control estimator developed by Abadie et al. (2010) and assessing the significance of the impact estimates using placebo tests, and secondly, by applying the traditional difference-in-differences estimator and using inference techniques based on individual-level data to assess the significance of the impact estimates. Both lead to the same conclusion: The immigration shock led to an overall negative, though short-lived, impact on the fertility of non-Cuban Miami residents, notably in the years 1983 and 1986. These results suggest that immigration shocks do have implications for the fertility decisions and outcomes of natives, though these tend only to be temporary and short-lived. There therefore appear to be little long-term or sustained consequences for the fertility of natives from governments pursuing labour augmenting strategies through more open immigration policies.

In addition, fertility effects are found to vary by homeownership: While the immigration shock had a negative impact on the fertility of women living in rented homes, it had practically no effect on women living in owned homes. This differential impact is likely due to the rise in local housing rents accompanying immigration, making childbearing activities less affordable for women living in rented homes. This suggests that the housing market is a key pathway through which immigration shocks affect native fertility.

Although it would have been insightful to examine whether fertility effects are heterogenous across skill levels, the tiny sample sizes which result when the sample is split by educational level (high school dropouts versus high school graduates and higher) prevent this analysis in practice. So I am unable to examine whether the fertility of high school dropouts was differently affected than those of high school graduates, an implication which Borjas' (2017a, b) findings would seem to suggest. More generally, this prevents me from examining whether the overall observed negative fertility effect might also be working through the labour market channel (job insecurity and wages) and therefore to comment on the plausibility of this mechanism.

Given the novelty of the research question posed by this paper and the exploratory nature of its findings, there is scope for future work to study in greater detail, the precise mechanisms through which immigration flows affect native childbearing activity.

\section{Endnotes}

${ }^{1}$ Although it is recognised that the impact of job insecurity on fertility will vary by characteristics such as sex, ethnicity, age, level of completed education and/or current family size, there is consensus within the fertility literature that "high levels of [economic] uncertainty are generally expected to have a negative influence on childbearing decisions" (Sobotka et al. 2011).

${ }^{2}$ Housing has been found to be a precondition for childbearing, especially in societies where nuclear living arrangements are the norm (Mulder 2006). 
${ }^{3}$ The Mariel Cubans were disproportionately low-skilled. Borjas' (2017a) estimates suggest that only $10 \%$ of them were college graduates while the overwhelming majority (60\%) were high school dropouts.

${ }^{4}$ Borjas (2017a) acknowledges that his finding of adverse wage effects increasing over time is puzzling since theory would predict that wage effects should be largest right after the immigration shock and should weaken with time as capital stock adjusts. However, he rationalises the finding by arguing that wages are sticky downward. Consequently, there might have been a lag before the largest wage effects show up in the labour market.

${ }^{5}$ Borjas (2017a) restricts his analysis to the least skilled workers-defined as nonHispanic men, aged 25-59, with less than high school education.

${ }^{6}$ Although there is potentially a difference in the way low-skilled and high-skilled women respond in terms of fertility behaviour to immigration shocks, the direction of this difference is unclear. The increased uncertainty among certain groups of natives (natives, in particular, who are low-skilled, and who might perceive their labour market opportunities to be weaker with the arrival of the Mariel Cubans) should work to impact fertility negatively since it might induce these natives to delay their childbearing plans in anticipation of tougher economic conditions in the future (Ranjan 1999; Sobotka et al. 2011). However, if wages of the low-skilled Miami women decline, (as suggested by Borjas' (2017a, b)), then fertility of this group might be positively affected since this would reduce the opportunity cost of childrearing.

${ }^{7}$ Considerable changes in the geographical definitions of metropolitan areas after 1988 limit the final year of analysis in this study to 1988. Data were unavailable for the years 1975 and 1978.

${ }^{8}$ To be exact, there were a total of 45 MSAs in the CPS dataset. However, 12 of these MSAs: Milwaukee, Phoenix, Columbus, Rochester, Sacramento, Fort Worth, Birmingham, Albany Schenectady Troy, Norfolk Portsmouth, Akron, Gary Hammond East Chicago, and Greensboro Winston Salem High Point, were created only after 1977. Also, 3 MSAs ceased to exist after 1985: Nassau Suffolk, Newark, and Patterson Clifton Passaic. These MSAs were therefore excluded from our analysis to ensure consistency in the control units throughout the period 1973-1988. Furthermore, the redefinition of MSAs after 1985 resulted in a number of preexisting MSAs being merged with other MSAs: A total of 3 mergers were created: (1) Anaheim Santa Ana Garden Grove-Los Angeles Long Beach, (2) San Bernardino Riverside Ontario-Los Angeles Long Beach, and (3) San Jose-San Francisco Oakland. Hence, observations from the 3 originally independent MSAs: Anaheim Santa Ana Garden Grove, San Bernardino Riverside Ontario, and San Jose, were subsumed into the combined entities. All in all, these meant that only 27 of the original 45 geographically identified MSAs were available for use.

${ }^{9}$ Between the years 1973 and 1988, approximately 20\% of childbirths in Miami occurred out of wedlock. This figure was approximately $13 \%$ for all US metropolitan areas.

${ }^{10}$ The literature exploring the relationship between economic activity and fertility has sometimes distinguished between short-term and permanent changes in fertility resulting from a contraction in economic activity. While the latter represents a quantum downward shift in fertility which will likely have consequences for completed fertility, the former usually arises from a shift in the timing of childbearing (i.e. postponement of childbearing) which is typically compensated in later years (Sobotka et al. 2011). 
${ }^{11}$ Each of the columns in the $(k x J)$ matrix is a data vector containing preintervention fertility outcomes and covariates predictive of metropolitan area fertility for a different metropolitan area.

${ }^{12}$ Where $j=2, \ldots ., J+1$ are the $J$ metropolitan areas potentially contributing to the synthetic control unit.

${ }^{13}$ Fertility outcomes are computed for the synthetic Miami by taking the weighted average of fertility outcomes pertaining to the metropolitan areas receiving positive weights.

${ }^{14}$ This is defined as the proportion of women between 15 and 44 years of age that are currently married and not separated from their spouses.

${ }^{15}$ As with all studies using difference-in-differences, we cannot preclude the possibility that the estimated fertility declines might have arisen as a result of some other unobserved shocks specific to Miami at the time (e.g. natural disasters, security threats) rather than due to the Mariel Boatlift. However, the analysis by homeownership status (see Section 4. 4.1) does provide some evidence that the Mariel shock had a role to play in the fertility changes, with the relationship operating through the housing price/rents channel.

${ }^{16}$ To verify if the observed declines in fertility in 1983 and 1986 had been planned and to ascertain if changes in childbearing decisions were indeed made at around the same time as when the Mariel Boatlift occurred, I additionally examine whether the childbearing intentions among Miami women changed after the Boatlift (Schoen et al. 1999). As with analysing changes in fertility outcomes, synthetic comparison controls for Miami were constructed to approximate how movements in the fertility intentions (as measured by the proportion of women in an MSA that expect to have more children in the years ahead) among non-Cuban women in Miami would have evolved in the absence of the Mariel Boatlift. Results from the analysis show that relative to the synthetic control, the actual proportion of women in Miami expecting to have additional children fell by approximately 7.6 and $11.9 \%$ respectively in 1981 and 1985-years that preceded the actual fertility declines.

${ }^{17}$ MSA-specific birth rates, fertility intentions, and MSA-specific characteristics were derived using data from the CPS.

${ }^{18}$ Subscripts denoting the individual and time are suppressed for simplicity.

${ }^{19}$ Initially, I included unemployment rates in the year of the survey and unemployment rates with a 2 -year lag as explanatory variables. However, these variables were always found to be jointly insignificant. Hence, they were removed from the regressions.

${ }^{20} \mathrm{An}$ increase in male unemployment rate in an MSA is expected to lower the likelihood of a birth occurring in that MSA, with a lag. Theory is unclear about how the likelihood of a birth in an MSA would change with an increase in female unemployment rate.

${ }^{21}$ The sample includes data over the period 1973-1988, with the exception of years 1975 and 1978.

${ }^{22}$ The full set of coefficient estimates for the regressions in Table 4 can be found in Appendix Table 6.

${ }^{23}$ Appendix Table 7 shows that these conclusions do not change even if we take instead all other unaffected MSAs to constitute the comparison group. A comparison group comprising all other MSAs (apart from Miami) captures national trends in fertility and economic conditions. 
${ }^{24}$ An average of only $0.74 \%$ of Miami women belonged to category (c) during the years $1980-1988$. Similarly, an average of only $0.82 \%$ of women in the US belonged to this category in $1980-1988$.

${ }^{25}$ The evolution of fertility rates among renters and homeowners in Miami and in the comparison MSAs is shown in Fig. 3.

${ }^{26}$ Here, only 9 years of data $(1980-1988)$ are considered. This is because information on homeownership was not available prior to 1980 . We take 1980-1981 to constitute the pre-treatment years and 1982-1988 to constitute the post-treatment period.

${ }^{27}$ Here, the synthetic control is constructed as a weighted combination of 3 metropolitan areas: Los Angeles, Indianapolis, and New Orleans. The precise contributions of the 3 metropolitan areas to the control unit are shown in panel B of Table 2. The same predictors used earlier to analyse fertility outcomes for women age 15-44 are used as characteristics of Miami for which the synthetic control should match (see panel B of Table 3). The results, derived using all other metropolitan areas to form the comparison group, are extremely similar to those found here and can be found in Appendix Table 8 (panel A).

${ }^{28}$ Here, the synthetic control is formed by a weighted average of 3 metropolitan areas: Philadelphia, Boston, and Tampa St. Petersburg. The contributions of these metropolitan areas to the synthetic control are given in panel $\mathrm{C}$ of Table 2. The same predictors used to analyse fertility outcomes for women age 15-44 are used as characteristics of Miami for which the synthetic control should match (see panel $\mathrm{C}$ of Table 3). The results, derived using all other metropolitan areas to form the comparison group, are extremely similar to those found here and can be found in Appendix Table 8 (panel A).

${ }^{29}$ Here, the synthetic control is constructed using the same metropolitan areas as those used in Section 4.2. The precise contributions of these metropolitan areas to the synthetic control are shown in panel A of Table 2. The results, derived using all other metropolitan areas to form the comparison group, are extremely similar to those found here and can be found in Appendix Table 8 (panel B).

${ }^{30}$ By estimating separate equations for homeowners and renters, I am implicitly allowing for the coefficients on all other regressors to differ for homeowners and renters. The analysis using the interaction terms with homeownership status is more restrictive since coefficients on all other regressors are restricted to be the same across both groups of women-homeowners and renters. However, sample sizes are larger with the interaction specification. In any case, both specifications yield similar conclusions: the Boatlift had a negative impact on the fertility of renters but little impact on homeowners.

${ }^{31}$ Dettling and Kearney (2014) found that an increase in housing prices decreases the birthrates of non-homeowners and increases the birthrates of homeowners. The latter potentially occurs because a rise in housing price increases home equity for owners. Home equity can, in turn, be extracted through mortgage refinancing or obtaining a home equity loan/line of credit. One reason I find less positive fertility impacts on homeowners in this paper (as compared to Dettling and Kearney) could be due to such loan instruments being less readily available in the 1980s - the time period in which this paper is based. 


\section{Appendix}

\section{Appendix 1}

Table 6 Full set of coefficient estimates for Table 4 regressions

\begin{tabular}{|c|c|c|c|c|c|}
\hline & (1) & (2) & (3) & (4) & (5) \\
\hline \multicolumn{6}{|l|}{ Separate-year treatment effects } \\
\hline \multirow[t]{2}{*}{1982} & 0.014 & 0.007 & 0.005 & 0.009 & 0.011 \\
\hline & $(0.025)$ & $(0.027)$ & $(0.027)$ & $(0.026)$ & $(0.026)$ \\
\hline \multirow[t]{2}{*}{1983} & $-0.041^{* *}$ & $-0.034^{*}$ & $-0.038^{*}$ & $-0.039^{*}$ & $-0.040^{*}$ \\
\hline & $(0.018)$ & $(0.021)$ & $(0.021)$ & $(0.020)$ & $(0.020)$ \\
\hline \multirow[t]{2}{*}{1984} & -0.007 & 0.007 & 0.004 & 0.004 & 0.005 \\
\hline & $(0.020)$ & $(0.023)$ & $(0.023)$ & $(0.023)$ & $(0.023)$ \\
\hline \multirow[t]{2}{*}{1985} & 0.012 & 0.006 & 0.005 & 0.008 & 0.008 \\
\hline & $(0.022)$ & $(0.023)$ & $(0.022)$ & $(0.022)$ & $(0.022)$ \\
\hline \multirow[t]{2}{*}{1986} & $-0.032^{* *}$ & $-0.036^{* *}$ & $-0.038^{* *}$ & $-0.039^{* *}$ & $-0.041^{* *}$ \\
\hline & $(0.015)$ & $(0.017)$ & $(0.017)$ & $(0.017)$ & $(0.017)$ \\
\hline \multirow[t]{2}{*}{1987} & 0.006 & 0.006 & 0.005 & 0.005 & 0.003 \\
\hline & $(0.017)$ & $(0.019)$ & $(0.019)$ & $(0.018)$ & $(0.018)$ \\
\hline \multirow[t]{2}{*}{1988} & 0.011 & 0.006 & 0.004 & 0.006 & 0.005 \\
\hline & $(0.017)$ & $(0.019)$ & $(0.019)$ & $(0.019)$ & $(0.018)$ \\
\hline \multicolumn{6}{|l|}{ Covariate } \\
\hline \multirow[t]{2}{*}{ Non-Hispanic African American } & - & -0.003 & -0.004 & 0.006 & 0.046 \\
\hline & & $(0.006)$ & $(0.006)$ & $(0.006)$ & $(0.030)$ \\
\hline \multirow[t]{2}{*}{ Other Race } & - & 0.022 & 0.023 & 0.016 & -0.080 \\
\hline & & $(0.016)$ & $(0.016)$ & $(0.016)$ & $(0.052)$ \\
\hline \multirow[t]{2}{*}{ Hispanic } & - & 0.008 & 0.000 & -0.010 & $0.075^{* *}$ \\
\hline & & $(0.008)$ & $(0.008)$ & $(0.008)$ & $(0.030)$ \\
\hline \multirow[t]{2}{*}{ Age 15} & - & $0.011^{* *}$ & $-0.013^{*}$ & $0.042^{* * *}$ & $0.049 * * *$ \\
\hline & & $(0.005)$ & $(0.007)$ & $(0.008)$ & $(0.008)$ \\
\hline \multirow[t]{2}{*}{ Age 16} & - & $0.013^{* *}$ & -0.005 & $0.047^{* * *}$ & $0.054^{* * *}$ \\
\hline & & $(0.006)$ & $(0.007)$ & $(0.008)$ & $(0.008)$ \\
\hline \multirow[t]{2}{*}{ Age 17} & - & $0.017^{* * *}$ & 0.003 & $0.053^{* * *}$ & $0.058^{* * *}$ \\
\hline & & $(0.006)$ & $(0.007)$ & $(0.007)$ & $(0.007)$ \\
\hline \multirow[t]{2}{*}{ Age 18} & - & $0.060^{* * *}$ & $0.052^{* * *}$ & $0.093^{* * *}$ & $0.097^{* * *}$ \\
\hline & & $(0.011)$ & $(0.011)$ & $(0.011)$ & $(0.011)$ \\
\hline \multirow[t]{2}{*}{ Age 19} & - & $0.082^{* * *}$ & $0.076^{* * *}$ & $0.111^{* * *}$ & $0.115^{* * *}$ \\
\hline & & $(0.013)$ & $(0.013)$ & $(0.013)$ & $(0.013)$ \\
\hline \multirow[t]{2}{*}{ Age 20} & - & $0.103^{* * *}$ & $0.101^{* * *}$ & $0.125^{* * *}$ & $0.130^{* * *}$ \\
\hline & & $(0.015)$ & $(0.015)$ & $(0.016)$ & $(0.016)$ \\
\hline \multirow[t]{2}{*}{ Age 21} & - & $0.110^{* * *}$ & $0.109^{* * *}$ & $0.128^{* * *}$ & $0.131^{* * *}$ \\
\hline & & $(0.015)$ & $(0.015)$ & $(0.015)$ & $(0.015)$ \\
\hline \multirow[t]{2}{*}{ Age 22} & - & $0.101^{* * *}$ & $0.100^{* * *}$ & $0.112^{* * *}$ & $0.116^{* * *}$ \\
\hline & & $(0.013)$ & $(0.013)$ & $(0.013)$ & $(0.013)$ \\
\hline \multirow[t]{2}{*}{ Age 23} & - & $0.123^{* * *}$ & $0.124^{* * *}$ & $0.130^{* * *}$ & $0.133^{* * *}$ \\
\hline & & $(0.015)$ & $(0.015)$ & $(0.015)$ & $(0.015)$ \\
\hline
\end{tabular}


Table 6 Full set of coefficient estimates for Table 4 regressions (Continued)

\begin{tabular}{|c|c|c|c|c|c|}
\hline & (1) & (2) & (3) & (4) & (5) \\
\hline \multirow[t]{2}{*}{ Age 24} & - & $0.124^{* * *}$ & $0.125^{* * *}$ & $0.125^{* * *}$ & $0.127^{* * *}$ \\
\hline & & $(0.015)$ & $(0.015)$ & $(0.015)$ & $(0.015)$ \\
\hline \multirow[t]{2}{*}{ Age 25} & - & $0.120^{* * *}$ & $0.121^{* * *}$ & $0.118^{* * *}$ & $0.120^{* * *}$ \\
\hline & & $(0.013)$ & $(0.014)$ & $(0.014)$ & $(0.014)$ \\
\hline \multirow[t]{2}{*}{ Age 26} & - & $0.120^{* * *}$ & $0.122^{* * *}$ & $0.118^{* * *}$ & $0.120^{* * *}$ \\
\hline & & $(0.014)$ & $(0.014)$ & $(0.014)$ & $(0.014)$ \\
\hline \multirow[t]{2}{*}{ Age 27} & - & $0.106^{* * *}$ & $0.109^{* * *}$ & $0.103^{* * *}$ & $0.106^{* * *}$ \\
\hline & & $(0.013)$ & $(0.013)$ & $(0.013)$ & $(0.013)$ \\
\hline \multirow[t]{2}{*}{ Age 28} & - & $0.132 * * *$ & $0.134^{* * *}$ & $0.128^{* * *}$ & $0.130^{* * *}$ \\
\hline & & $(0.015)$ & $(0.015)$ & $(0.015)$ & $(0.015)$ \\
\hline \multirow[t]{2}{*}{ Age 29} & - & $0.095^{* * *}$ & $0.099^{* * *}$ & $0.087^{* * *}$ & $0.089^{* * *}$ \\
\hline & & $(0.012)$ & $(0.012)$ & $(0.012)$ & $(0.012)$ \\
\hline \multirow[t]{2}{*}{ Age 30} & - & $0.116^{* * *}$ & $0.120^{* * *}$ & $0.108^{* * *}$ & $0.110^{* * *}$ \\
\hline & & $(0.015)$ & $(0.015)$ & $(0.014)$ & $(0.014)$ \\
\hline \multirow[t]{2}{*}{ Age 31} & - & $0.108^{* * *}$ & $0.112^{* * *}$ & $0.102^{* * *}$ & $0.103^{* * *}$ \\
\hline & & $(0.015)$ & $(0.015)$ & $(0.014)$ & $(0.014)$ \\
\hline \multirow[t]{2}{*}{ Age 32} & - & $0.088^{* * *}$ & $0.091^{* * *}$ & $0.079^{* * *}$ & $0.081^{* * *}$ \\
\hline & & $(0.013)$ & $(0.013)$ & $(0.013)$ & $(0.013)$ \\
\hline \multirow[t]{2}{*}{ Age 33} & - & $0.053^{* * *}$ & $0.057^{* * *}$ & $0.049^{* * *}$ & $0.050^{* * *}$ \\
\hline & & $(0.008)$ & $(0.008)$ & $(0.008)$ & $(0.008)$ \\
\hline \multirow[t]{2}{*}{ Age 34} & - & $0.087^{* * *}$ & $0.090^{* * *}$ & $0.081^{* * *}$ & $0.081^{* * *}$ \\
\hline & & $(0.014)$ & $(0.014)$ & $(0.014)$ & $(0.015)$ \\
\hline \multirow[t]{2}{*}{ Age 35} & - & $0.043^{* * *}$ & $0.047^{* * *}$ & $0.040^{* * *}$ & $0.041^{* * *}$ \\
\hline & & $(0.010)$ & $(0.010)$ & $(0.010)$ & $(0.010)$ \\
\hline \multirow[t]{2}{*}{ Age 36} & - & $0.031^{* * *}$ & $0.035^{* * *}$ & $0.028^{* * *}$ & $0.030^{* * *}$ \\
\hline & & $(0.007)$ & $(0.007)$ & (0.008) & (0.008) \\
\hline \multirow[t]{2}{*}{ Age 37} & - & $0.030^{* * *}$ & $0.035^{* * *}$ & $0.029^{* * *}$ & $0.030^{* * *}$ \\
\hline & & $(0.008)$ & $(0.008)$ & $(0.008)$ & $(0.009)$ \\
\hline \multirow[t]{2}{*}{ Age 38} & - & $0.031^{* * *}$ & $0.035^{* * *}$ & $0.028^{* * *}$ & $0.029^{* * *}$ \\
\hline & & $(0.009)$ & $(0.009)$ & (0.009) & (0.009) \\
\hline \multirow[t]{2}{*}{ Age 39} & - & $0.017^{* * *}$ & $0.021^{* * *}$ & $0.015^{* *}$ & $0.015^{* *}$ \\
\hline & & $(0.006)$ & $(0.006)$ & $(0.007)$ & $(0.007)$ \\
\hline \multirow[t]{2}{*}{ Age 40} & - & $0.031^{* * *}$ & $0.035^{* * *}$ & $0.030^{* * *}$ & $0.031^{* * *}$ \\
\hline & & $(0.010)$ & $(0.010)$ & $(0.010)$ & $(0.010)$ \\
\hline \multirow[t]{2}{*}{ Age 41} & - & $0.015^{* *}$ & $0.017^{* * *}$ & $0.015^{* *}$ & $0.015^{* *}$ \\
\hline & & $(0.007)$ & $(0.007)$ & $(0.007)$ & $(0.007)$ \\
\hline \multirow[t]{2}{*}{ Age 42} & - & 0.005 & $0.008^{* *}$ & $0.010^{* *}$ & $0.012^{* *}$ \\
\hline & & $(0.003)$ & $(0.003)$ & $(0.005)$ & $(0.005)$ \\
\hline \multirow[t]{2}{*}{ Age 43} & - & 0.001 & 0.003 & 0.005 & 0.006 \\
\hline & & $(0.002)$ & $(0.002)$ & $(0.004)$ & $(0.004)$ \\
\hline \multirow[t]{2}{*}{$\$ 5000$ to $\$ 7499$} & - & $-0.021^{*}$ & $-0.019^{*}$ & $-0.026^{* *}$ & $-0.026^{* *}$ \\
\hline & & $(0.012)$ & $(0.012)$ & $(0.011)$ & $(0.011)$ \\
\hline
\end{tabular}


Table 6 Full set of coefficient estimates for Table 4 regressions (Continued)

\begin{tabular}{|c|c|c|c|c|c|}
\hline & (1) & $(2)$ & (3) & (4) & (5) \\
\hline \multirow[t]{2}{*}{$\$ 7500$ to $\$ 9999$} & - & $-0.025^{* *}$ & $-0.023^{* *}$ & $-0.036^{* * *}$ & $-0.034^{* * *}$ \\
\hline & & $(0.011)$ & $(0.011)$ & $(0.011)$ & $(0.011)$ \\
\hline \multirow[t]{2}{*}{$\$ 10,000$ to $\$ 14,999$} & - & $-0.032^{* * *}$ & $-0.028^{* * *}$ & $-0.040^{* * *}$ & $-0.037^{* * *}$ \\
\hline & & $(0.009)$ & $(0.009)$ & $(0.009)$ & $(0.009)$ \\
\hline \multirow[t]{2}{*}{$\$ 15,000$ to $\$ 24,999$} & - & $-0.025^{* * *}$ & $-0.018^{* *}$ & $-0.040^{* * *}$ & $-0.036^{* * *}$ \\
\hline & & $(0.009)$ & $(0.009)$ & $(0.009)$ & $(0.009)$ \\
\hline \multirow[t]{2}{*}{$\$ 25,000$ and above } & - & $-0.032^{* * *}$ & $-0.020^{* *}$ & $-0.052^{* * *}$ & $-0.049^{* * *}$ \\
\hline & & $(0.009)$ & $(0.009)$ & $(0.009)$ & $(0.009)$ \\
\hline \multirow[t]{2}{*}{ Male unemployment rate, $t-1$} & - & $-0.199 * *$ & $-0.185^{*}$ & $-0.181^{*}$ & $-0.183^{*}$ \\
\hline & & $(0.099)$ & $(0.099)$ & $(0.097)$ & $(0.097)$ \\
\hline \multirow[t]{2}{*}{ Female unemployment rate, $t-1$} & - & -0.094 & -0.078 & -0.079 & -0.088 \\
\hline & & $(0.130)$ & $(0.130)$ & $(0.128)$ & $(0.128)$ \\
\hline \multirow[t]{2}{*}{ Number of previous births } & - & 0.002 & 0.000 & $-0.008^{* * *}$ & $-0.007^{* * *}$ \\
\hline & & $(0.002)$ & $(0.002)$ & $(0.002)$ & $(0.002)$ \\
\hline \multirow[t]{2}{*}{ Years of education } & - & - & $-0.005^{* * *}$ & $-0.004^{* * *}$ & $-0.003^{* *}$ \\
\hline & & & $(0.001)$ & $(0.001)$ & $(0.001)$ \\
\hline \multirow[t]{2}{*}{ Married } & - & - & - & $0.103^{* * *}$ & $0.118^{* * *}$ \\
\hline & & & & $(0.006)$ & $(0.006)$ \\
\hline \multirow{2}{*}{$\begin{array}{l}\text { Years of education } \times \text { non-Hispanic } \\
\text { African American }\end{array}$} & - & - & - & - & -0.001 \\
\hline & & & & & $(0.002)$ \\
\hline \multirow[t]{2}{*}{ Years of education $\times$ other race } & - & - & - & - & 0.006 \\
\hline & & & & & $(0.004)$ \\
\hline \multirow[t]{2}{*}{ Years of education $\times$ Hispanic } & - & - & - & - & $-0.006^{* * *}$ \\
\hline & & & & & $(0.002)$ \\
\hline \multirow{2}{*}{$\begin{array}{l}\text { Married } \times \text { non-Hispanic African } \\
\text { American }\end{array}$} & - & - & - & - & $-0.059^{* * *}$ \\
\hline & & & & & $(0.011)$ \\
\hline \multirow[t]{2}{*}{ Married $\times$ other race } & - & - & - & - & 0.031 \\
\hline & & & & & $(0.026)$ \\
\hline \multirow[t]{2}{*}{ Married $\times$ Hispanic } & - & - & - & - & -0.023 \\
\hline & & & & & $(0.014)$ \\
\hline Observations & 71,571 & 58,921 & 58,921 & 58,921 & 58,921 \\
\hline$R$-squared & 0.002 & 0.035 & 0.037 & 0.064 & 0.067 \\
\hline \multicolumn{6}{|c|}{$\begin{array}{l}\text { Sample consists of women age } 15-44 \text {. The comparison group encompasses all observations from New York, Chicago, } \\
\text { Philadelphia, Baltimore, Cleveland, Houston, San Diego, New Orleans, Tampa St. Petersburg, and Portland. Sample weights are } \\
\text { used in all regressions. All specifications are estimated by OLS. Robust standard errors are in parentheses. The dependent variable } \\
\text { is whether or not an individual has had a birth in the last } 12 \text { months. Ethnicity is represented by } 4 \text { indicator variables-non- } \\
\text { Hispanic White, non-Hispanic African American, other race, and Hispanic (with non-Hispanic White as the base group). } \\
\text { Age is represented by } 30 \text { dummies-one for every age (with age } 44 \text { as the base category). Family income is represented by } 6 \\
\text { indicator variables-less than } \$ 5000, \$ 5000 \text { to } \$ 7499, \$ 7500 \text { to } \$ 9999, \$ 10,000 \text { to } \$ 14,999, \$ 15,000 \text { to } \$ 24,999 \text {, and } \$ 25,000 \text { and } \\
\text { above (with less than US\$5000 per annum as the base category). Marital status is represented by a dichotomous variable-either } \\
\text { currently married or not. MSA and Year dummies are included in all regressions. }{ }^{* * *} p \text { value }<0.01, * * p \text { value }<0.05,{ }^{*} p \text { value }<0.1\end{array}$} \\
\hline
\end{tabular}




\section{Appendix 2}

Table 7 Estimated impacts of Mariel Boatlift (using all other unaffected MSAs as the comparison)

\begin{tabular}{clllll}
\hline & $(1)$ & $(2)$ & $(3)$ & $(4)$ & $(5)$ \\
Included covariates & $(\mathrm{a})-(\mathrm{b})$ & $(\mathrm{a})-(\mathrm{f})$ & $(\mathrm{a})-(\mathrm{g})$ & $(\mathrm{a})-(\mathrm{h})$ & $(\mathrm{a})-(\mathrm{i})$ \\
\hline Separate-year treatment effects & & & & & \\
1982 & 0.014 & 0.008 & 0.007 & 0.008 & 0.010 \\
& $(0.024)$ & $(0.026)$ & $(0.026)$ & $(0.025)$ & $(0.025)$ \\
1983 & $-0.036^{* *}$ & $-0.034^{*}$ & $-0.035^{*}$ & $-0.037^{* *}$ & $-0.037^{* *}$ \\
& $(0.017)$ & $(0.018)$ & $(0.018)$ & $(0.018)$ & $(0.018)$ \\
1984 & -0.007 & 0.003 & 0.002 & 0.000 & 0.001 \\
& $(0.019)$ & $(0.022)$ & $(0.022)$ & $(0.021)$ & $(0.021)$ \\
1985 & 0.014 & 0.009 & 0.009 & 0.010 & 0.010 \\
& $(0.021)$ & $(0.022)$ & $(0.022)$ & $(0.022)$ & $(0.022)$ \\
1986 & $-0.025^{*}$ & -0.022 & -0.023 & -0.024 & $-0.026^{*}$ \\
& $(0.014)$ & $(0.016)$ & $(0.016)$ & $(0.015)$ & $(0.015)$ \\
1987 & -0.006 & 0.000 & 0.000 & 0.001 & -0.001 \\
& $(0.016)$ & $(0.018)$ & $(0.018)$ & $(0.017)$ & $(0.017)$ \\
1988 & 0.008 & 0.011 & 0.010 & 0.013 & 0.012 \\
& $(0.016)$ & $(0.018)$ & $(0.018)$ & $(0.018)$ & $(0.018)$ \\
Observations & 184,312 & 151,408 & 151,408 & 151,408 & 151,408 \\
R-squared & 0.001 & 0.033 & 0.034 & 0.066 & 0.068 \\
\hline
\end{tabular}

Sample consists of women age 15-44. The comparison group encompasses observations from all identified metropolitan areas except Miami. The control variables in column (1) include MSA and year dummies. The control variables in column (2) include MSA, year, age, ethnicity, and family income dummy variables as well as the number of previous births by the individual and MSA-level lagged male and female unemployment rates. The control variables in column (3) include all the control variables in column (2) plus the level of completed education of an individual. The control variables in column (4) include all the control variables in column (3) plus a dummy variable for marital status. The control variables in column (5) include all the control variables in column (4) plus an interaction term for ethnicity and education and an interaction term for ethnicity and marital status. Sample weights are used in all regressions. All specifications are estimated by OLS. Robust standard errors are in parentheses. ${ }^{* *} p$ value $<0.01,{ }^{* *} p$ value $<0.05,{ }^{*} p$ value $<0.1$ 


\section{Appendix 3}

Table 8 Estimated impacts of Boatlift on fertility of women living in rented and in owned homes (using all other unaffected MSAs as the comparison)

\begin{tabular}{|c|c|c|c|c|}
\hline \multirow[b]{4}{*}{ Included covariates } & \multicolumn{2}{|l|}{ Panel A } & \multicolumn{2}{|l|}{ Panel B } \\
\hline & (1) & (2) & (3) & (4) \\
\hline & Renters & Homeowners & Renters & Homeowners \\
\hline & (a)-(i) & (a)-(i) & (a)-(i) & (a)-(i) \\
\hline \multicolumn{5}{|c|}{ Separate-year treatment effects } \\
\hline \multirow[t]{2}{*}{1982} & -0.022 & 0.022 & 0.007 & -0.006 \\
\hline & $(0.043)$ & $(0.036)$ & $(0.038)$ & $(0.035)$ \\
\hline \multirow[t]{2}{*}{1983} & $-0.108^{* * *}$ & 0.009 & $-0.082^{* * *}$ & -0.018 \\
\hline & $(0.031)$ & $(0.031)$ & $(0.023)$ & $(0.030)$ \\
\hline \multirow[t]{2}{*}{1984} & $-0.086^{* * *}$ & 0.058 & $-0.054^{* *}$ & 0.030 \\
\hline & $(0.033)$ & $(0.036)$ & $(0.026)$ & $(0.035)$ \\
\hline \multirow[t]{2}{*}{1985} & -0.009 & 0.005 & 0.023 & -0.031 \\
\hline & $(0.040)$ & $(0.026)$ & $(0.035)$ & $(0.025)$ \\
\hline \multirow[t]{2}{*}{1986} & $-0.070^{* *}$ & -0.004 & $-0.049^{* *}$ & -0.030 \\
\hline & $(0.032)$ & $(0.024)$ & $(0.025)$ & $(0.022)$ \\
\hline \multirow[t]{2}{*}{1987} & -0.039 & 0.019 & -0.018 & -0.007 \\
\hline & $(0.034)$ & $(0.027)$ & $(0.027)$ & $(0.026)$ \\
\hline \multirow[t]{2}{*}{1988} & -0.020 & 0.020 & 0.004 & -0.006 \\
\hline & $(0.034)$ & $(0.026)$ & $(0.028)$ & $(0.025)$ \\
\hline Observations & 47,374 & 67,903 & 115,277 & \\
\hline$R$-squared & 0.067 & 0.076 & 0.068 & \\
\hline
\end{tabular}

The estimated treatment effects in panel A are obtained by estimating Eq. (3), separately for the sample of renters (column (1)) and homeowners (column (2)). The estimated treatment effects in panel B are obtained from estimating Eq. (4). Equation (4) includes variables where the post-treatment year-Miami terms are interacted with a dummy indicating homeownership status. In all cases, the comparison groups encompass observations from all identified metropolitan areas except Miami. In all regressions, we include as control variables the following: MSA, year, age, ethnicity, marital status, and family income dummy variables as well as the number of previous births by an individual, the MSA-level lagged male and female unemployment rates, the level of completed education of an individual, an interaction term for ethnicity and education and an interaction term for ethnicity and marital status. Sample weights are used in all regressions. All specifications are estimated by OLS. Robust standard errors are in parentheses. ${ }^{* * *} p$ value $<0.01,{ }^{* *} p$-value $<0.05$

\section{Acknowledgements}

I am grateful to the editor Jackline Wahba and to an anonymous referee for their helpful suggestions and comments. I am indebted to Steven Stillman, Tarja Viitanen, and Murat Genç for their invaluable mentorship and advice. I also thank Barry Chiswick, David McKenzie, and participants of the 1st IZA@DC Young Scholar Program for insightful comments. All errors are mine.

Responsible editor: Jackline Wahba

\section{Funding}

Not applicable

Availability of data and materials

I commit to providing my data in publicly available repositories if my manuscript is accepted for publication.

Ethics approval and consent to participate

Not applicable

Consent for publication

Not applicable

\section{Competing interests}

The IZA Journal of Development and Migration is committed to the IZA Guiding Principles of Research Integrity. The author declares that he has observed these principles. 


\section{Publisher's Note}

Springer Nature remains neutral with regard to jurisdictional claims in published maps and institutional affiliations.

\section{Received: 19 July 2017 Accepted: 27 March 2018}

Published online: 27 September 2018

\section{References}

Abadie A, Diamond A, Hainmueller J. Synthetic control methods for comparative case studies: estimating the effect of California's tobacco control program. J Am Stat Assoc. 2010;105(490):493-505.

Abadie A, Gardeazabal J. The economic costs of conflict: a case study of the Basque Country. Am Econ Rev. 2003;93(1):113-32. Adsera A. Changing fertility in developed countries. The impact of labor market institutions. J Popul Econ. 2004;17(1):17-43. Adsera A, Menendez A. Fertility changes in Latin America in periods of economic uncertainty. Popul Stud. 2011;65(1):37-56 Bhaumik SK, Nugent JB. Real options and demographic decisions: empirical evidence from East and West Germany. Appl Econ. 2011;43(21):2739-49.

Blau FD, Mackie C, editors. The economic and fiscal consequences of immigration. Washington DC: National Academies Press; 2017.

Bohn S, Lofstrom M, Raphael S. Did the 2007 Legal Arizona Workers Act reduce the state's unauthorized immigrant population? Rev Econ Stat. 2014:96(2):258-69.

Borjas GJ. The wage impact of the Marielitos: a reappraisal. ILR Rev. 2017a;70(5):1077-110.

Borjas, George J. (2017b) Still more on Mariel: the role of race. NBER working paper 23504, June.

Borjas, George J. and Monras, Joan (2016) The labor market consequences of refugee supply shocks. NBER working paper 22656, September.

Card D. The impact of the Mariel Boatlift on the Miami labor market. Ind Labor Relat Rev. 1990;43(2):245-57.

Clemens and Hunt. (2017) The labor market effects of refugee waves: reconciling conflicting results. NBER working paper 23433, July.

Cortes P. The effect of low-skilled immigration on U.S. prices: evidence from CPI data. J Polit Econ. 2008;116(3):381-422.

Cortes P, Tessada J. Low-skilled immigration and the labor supply of highly skilled women. Am Econ J: Applied Economics. 2011;3(3):88-123.

Daniels JP, Von der Ruhr M. The determinants of immigration-policy preferences in advanced economies: a cross country study. Atl Econ J. 2003;31(2):146-58.

Dettling LJ, Kearney MS. House prices and birth rates: the impact of the real estate market on the decision to have a baby. J Public Econ. 2014;110:82-100.

Dustmann C, Preston I. Racial and economic factors in attitudes to immigration. BE J. Econ. Anal. Policy. 2007;7(1):Article 62.

Furtado D. Fertility responses of high-skilled native women to immigrant inflows. Demography. 2016;53(1):27-53.

Furtado D, Hock H. Low skilled immigration and work-fertility tradeoffs among high skilled US natives. Am Econ Rev. 2010;100(2):224-8

Gonzalez L, Ortega F. Immigration and housing booms: evidence from Spain. J Reg Sci. 2013;53(1):37-59.

Hondroyiannis G. Fertility determinants and economic uncertainty: an assessment using European panel data. J Fam Econ Iss. 2010;31(1):33-50

Lach S. Immigration and prices. J Polit Econ. 2007;115(4):548-87.

Lovenheim MF, Mumford KJ. Do family wealth shocks affect fertility choices? Evidence from the housing market. Rev Econ Stat. 2013:95(2):464-75.

Mayda AM. Who is against immigration? A cross-country investigation of individual attitudes towards immigrants. Rev Econ Stat. 2006;88(3):510-30.

Mulder CH. Population and housing: a two-sided relationship. Demogr Res. 2006:15(13):401-12.

Namboodiri K. A primer of population dynamics. New York: Plenum Press; 1996.

O'Donoghue C, O'Shea E. Fertility decline in Ireland. In: Gustafsson S, Kalwij A, editors. Education and postponement of maternity: economic analyses for industrialized countries. Dordrecht: Springer; 2006. p. 87-112.

Ottaviano G, Peri G. The effects of immigration on U.S. wages and rents: a general equilibrium approach. In: Nijkamp P, Poot J, Sahin M, editors. Migration impact assessment: new horizons. Cheltenham: Edward Elgar Pub. Ltd; 2012. p. 107-46.

Peri, Giovanni and Yasenov, Vasil. (2017) The labor market effects of a refugee wave: applying the synthetic control method to the Mariel Boatlift. NBER working paper 21801, June.

Ranjan P. Fertility behaviour under income uncertainty. Eur J Popul. 1999;15(1):25-43.

Saiz A. Room in the kitchen for the melting pot: immigration and rental prices. Rev Econ Stat. 2003:85(3):502-21.

Saiz A. Immigration and housing rents in American cities. J Urban Econ. 2007;61(2):345-71.

Scheve KF, Slaughter MJ. Labor market competition and individual preferences over immigration policy. Rev Econ Stat. 2001;83(1):133-45

Schoen R, Astone NM, Kim YJ, Nathanson CA, Fields JM. Do fertility intentions affect fertility behavior? J Marriage Fam. 1999;61(3):790-9.

Simon CJ, Tamura R. Do higher rents discourage fertility? Evidence from U.S. cities, 1940-2000. Reg Sci Urban Econ. 2009;39(1):33-42.

Sobotka T, Skirbekk V, Philipov D. Economic recession and fertility in the developed world. Popul Dev Rev. 2011;37(2):267-306

Willis RJ. A theory of out-of-wedlock childbearing. J Polit Econ. 1999;107(6):S33-64.

Yi JJ, Zhang J. The effect of house price on fertility: evidence from Hong Kong. Econ Inq. 2010;48(3):635-50. 